\title{
Financial Frictions, Financial Shocks, and Aggregate Volatility*
}

\author{
Cristina Fuentes-Albero ${ }^{\dagger}$ \\ Rutgers University
}

First version: November 2009

This version: January 2012

\begin{abstract}
The two main empirical regularities regarding US postwar nominal and real business cycles are the Great Inflation and the Great Moderation. While the volatility of financial price variables also follows such pattern, financial quantity variables have experienced a continuous immoderation. We examine these patterns in volatility by estimating a DSGE model with financial frictions and financial shocks allowing for structural breaks in the size of shocks and the institutional framework. We conclude that $(i)$ while the Great Inflation was driven by bad luck, the Great Moderation is mostly due to better financial institutions; ( $i i$ ) financial shocks are the main drivers of financial variables, investment, and the nominal interest rate and play a secondary role as drivers of consumption, output, inflation, and hours worked; (iii) investmentspecific technology shocks play an almost negligible role as drivers of the US business cycle.
\end{abstract}

Keywords: Great Moderation, Financial Immoderation, financial frictions, financial shocks, structural break, Bayesian methods

JEL Classification: E32, E44, C11, C13

${ }^{*}$ I thank Frank Schorfheide, Jesús Fernández-Villaverde, Maxym Kryshko, Leonardo Melosi, and Raf Wouters for their comments and suggestions. The author acknowledges the financial support from the Bank of Spain for part of this project. Usual disclaimers apply. This paper was previously circulating under the title Financial Frictions, the Financial Immoderation, and the Great Moderation

${ }^{\dagger}$ cfuentes@econ.rutgers.edu. Department of Economics, Rutgers University, 75 Hamilton St, New Brunswick, NJ, 08901. 


\section{Introduction}

The two main empirical regularities characterizing recent economic history in the US are the Great Inflation and the Great Moderation. The former refers to the decade of high level and large volatility of inflation and nominal interest rates that started in $1970^{1}$. Fluctuations at business cycle frequencies of real and financial variables also became wider in the 1970s. The Great Moderation stands for the observed slowdown in the volatility of real and nominal variables since the mid 1980s. During this period, volatilities of financial variables present the following dichotomy. On the one hand, fluctuations at business cycle frequencies for price variables such as credit spreads are milder. On the other hand, volatilities of quantity variables such as business net worth, household wealth, and deposits show an additional immoderation with respect to their values in the 1970s.

In this paper, we account for those patterns in volatility by means of a structural model. Following Christiano, Motto, and Rostagno (2003), we consider a model featuring a standard set of real and nominal frictions as in Smets and Wouters (2007), extended to accommodate financial rigidities as in Bernanke, Gertler, and Gilchrist (1999, BGG hereafter). We include two financial shocks affecting the spillovers of credit market imperfections on the economy. This theoretical framework allows us to quantify the relative role played by financial factors, monetary policy, and economic shocks in shaping the evolution of aggregate volatility. To do so, we estimate our model using a data set containing real, nominal, and financial variables. To account for the breaks in the second moments of the data, we allow for structural breaks in the size of shocks and the institutional framework. In particular, not only monetary policy coefficients, but also parameters governing financial rigidities are subject to structural breaks. In our model, the financial system is summarized by the average level of financial rigidity, measured by the marginal bankruptcy cost, and the unconditional mean of the external finance premium.

As in BGG, we assume that asymmetric information between borrowers and lenders arises because the return to capital depends not only on aggregate but also on idiosyncratic risk. While borrowers freely observe the realization of their idiosyncratic productivity shock, lenders must pay monitoring costs to observe the realized return of a borrower. To minimize monitoring costs, lenders audit borrowers only when they report their inability to pay the

\footnotetext{
${ }^{1}$ The Great Inflation has traditionally been dated from 1965 to 1982 . In our data set, however, the structural breaks in volatility for inflation are in 1970 and 1981. Therefore, we use the term Great Inflation to refer to such decade.
} 
loan back under the terms of the contract. In order to be compensated for the risk of default, lenders extend loans at a premium over the risk-free interest rate.

The external finance premium is at the heart of the mechanics operating in the financial accelerator. The premium is driven by two channels: the balance-sheet channel and the information channel. The balance-sheet channel captures the dependence of external financing opportunities on the composition of firms' balance sheets. The information channel implies that the external finance premium is a positive function of the severity of the agency problem. We enrich the DSGE model by introducing financial shocks affecting those two channels. Exogenous shocks to the balance-sheet channel are introduced in the form of wealth shocks. Shocks to the information channel are modeled as innovations affecting the parameter governing agency costs. While wealth shocks are included in many studies on the financial accelerator model, time variation in marginal bankruptcy costs has not been explored in the literature. However, using firm-level data and a partial equilibrium financial accelerator model, Levin, Natalucci, and Zakrajšek (2004) provided empirical evidence of time-varying bankruptcy costs. We find that, in order to account for the dynamics of credit spreads, it is crucial to assume that the marginal bankruptcy cost is a drifting parameter.

We estimate the model economy using Bayesian techniques on a standard data set of real and nominal variables extended to include two financial series: firms' net worth and the external finance premium. We need to take a stand on defining the empirical equivalent to such model variables. We focus on the data provided by the Flow of Funds Accounts to define net worth as tangible assets minus credit market liabilities for the nonfarm business sector, measured in real per capita terms. Our measure for the external finance premium is given by the spread between the Baa corporate rate and the federal funds rate. The data set ranges from 1954 to 2006. Most of the contributions to the empirical literature on the financial accelerator focus on data from the Volcker-Greenspan era. Besides the study of the Great Depression by Christiano, Motto, and Rostagno (2003), the only reference using pre-1980 data is the recent work by Gilchrist, Ortiz, and Zakrajšek (2009), whose sample spans from 1973 to 2008. They do not address, however, the break in the second moments of the data observed in the mid 1980s.

Conversely to the standard approach in the literature, we estimate the deep parameters characterizing the debt contract between borrowers and lenders. To the best of our knowledge, the most complete estimation exercise of a model including the financial accelerator is the one by Christiano, Motto, and Rostagno (2010). They fix two of the parameters we proceed to estimate in this paper: the survival probability and the fraction of realized profits 
lost in bankruptcy, that is, the average marginal bankruptcy cost.

The main empirical findings of the paper are the following. First of all, our posterior estimates state that (i) the size of real and nominal shocks increased during the Great Inflation and decreased in the mid-1980s; (ii) financial shocks have become lager over time; (iii) while the reaction of the monetary authority to deviations of output growth is tighter since the 1970s, the coefficient governing the response to inflation is only larger during the Great Moderation; (iv) financial rigidities were larger during the Great Inflation than in the previous decades, but since the 1980s the model economy operates, at the steady state, under an almost frictionless financial sector; and $(v)$ the average cost of external financing has been increasing since the beginning of the sample.

Second, our model provides a good fit of the data since it successfully accounts for the observed swings in aggregate volatility. While the Great Inflation was mostly due to bad luck, the smoother business cycle fluctuations since the mid 1980s are the result of a better institutional framework. But, while the estimated reduction in the unconditional average level of financial rigidities can deliver, depending on the variable, between $25 \%$ and $100 \%$ of the observed slowdown in volatilities, the role played by changes in the conduct of monetary policy is relatively small. The reduction in the size of the financial friction suffices to account for over $50 \%$ of the model implied slowdown in investment, around $35 \%$ of that in output, and hours, $23 \%$ of the reduction in the volatility of consumption and inflation, $78 \%$ of that in the nominal interest rate, and all of the reduction in the volatility of the credit spread. The immoderation in business wealth is accounted for by larger financial shocks and a higher average credit spread.

Finally, financial shocks play a significant role in shaping aggregate volatility. On the one hand, they are the main driver of the variance of financial variables, investment, and the nominal interest rate. On the other hand, they are a solid second on board driving the variance of output, consumption, hours, and inflation. Our results regarding the relevance of the investment-specific technology shock as driver of the business cycle point towards an overstatement of its relative contribution in the literature. In particular, once financial frictions and financial shocks are at play, the investment-specific technology shock is just a price shifter affecting the relative price of investment with respect to consumption. As such, it is only seemingly relevant as a driver of nominal variables and business wealth.

Recently, Justiniano, Primiceri, and Tambalotti (2011) studied two investment-specific technology shocks: one affecting the transformation of consumption into investment goods 
and another one affecting the transformation of investment goods into capital. Our investmentspecific technology shock coincides with the former, while our financial shocks would be captured, in reduced-form by their shock to the marginal efficiency of investment. Justiniano, Primiceri, and Tambalotti (2011) also conclude that the price shifter plays an almost negligible role once their proxy for fundamental disturbances to the functioning of the financial sector, i.e., shocks to the marginal efficiency of investment, are at play. Given that our model incorporates explicitly a financial sector and shocks originating in the financial sector, we can argue that we provide a foundation for the so-called shocks to the marginal efficiency of investment.

The plan of the paper is as follows. Section 2 presents the empirical evidence that motivates the paper. We describe the model in Section 3. Section 4 discusses the choice of parameters allowed to change over time. We describe the estimation procedure and report the estimation results in Section 5. Section 6 analyzes the drivers of the divergent patterns in volatility. In Section 7, we study the relative importance of each shock and the propagation of financial shocks. Section 8 concludes.

\section{Empirical Motivation}

We revisit the two empirical regularities characterizing the US over the 1954-2006 period which are the Great Inflation and the Great Moderation. We consider data until 2006 to avoid distortions due to non-linearities induced by the zero lower bound on the federal funds rate and binding downward nominal rigidities during the 2007-2009 recession. We document that while the volatility of real, nominal, and financial price variables follow the same pattern, some financial quantity measures and real hourly wages have experienced a sustained immoderation over time. In this section, we consider the following set of variables: output, investment, consumption, hourly wage, hours worked, inflation, federal funds rate, net worth for firms and households, demand deposits, checkable deposits, net private savings, the Wilshire 5000 index, and three credit spreads: the spread between the Baa corporate rate and the Aaa corporate rate, between Baa and the federal funds rate, and between Baa and the 10 year bond yield ${ }^{2}$.

Following McConnell and Pérez-Quirós (2000), we estimate the timing of the structural breaks in the residual variance of the raw variables and their cyclical counterpart by running an $\mathrm{AR}(1)$ model with drift on the variables of interest. Assuming that the error of the

\footnotetext{
${ }^{2}$ See the online Appendix for a full description of the data.
} 
$\operatorname{AR}(1)$ model, $\varepsilon_{t}$, follows a normal distribution, we can ensure that $\left[\left|\widehat{\varepsilon}_{t}\right| \sqrt{\pi / 2}\right]$ is an unbiased estimator for the residual standard deviation of the variable under analysis. We perform Bai and Perron (1998) tests to estimate the dating and the number of breaks in the standard deviation. The results for the Bai-Perron tests are reported in Table A-1. While for the volatility of nominal variables and spreads we can reject the null of parameter constancy in two different dates, we can only reject the null once for real and financial quantity variables. Nominal variables clearly provide 1970 as the starting point of the Great Inflation and the end of its aftermath in early 1980s. The break in the volatility of real variables is also quite uniform pointing toward the second quarter of 1984 as the start of the Great Moderation. Financial quantity measures provide a wide array of dates for the spin off of their increase in volatility.

In order to economize in the number of parameters to estimate in the structural estimation exercise, we restrict ourselves to consider two structural breaks in the data set at given dates. In particular, we consider the first break the estimated starting point for the Great Inflation and the second break the estimated beginning of the Great Moderation. In order to determine whether this approach is supported by the data, we run Chow (1960)'s tests using 1970:Q1 and 1984:Q2 as the breakpoints. We report the log-likelihood ratio statistic for both raw and cyclical data in the last two columns of Table A-1. We conclude that we can reject the null of parameter constancy at both dates for all variables under analysis but household wealth. Therefore, by focusing our analysis in the following three sub-samples 1954:Q4-1971:Q1, 1971:Q2-1984:Q2, and 1984:Q3-2004:Q4, we are not misrepresenting the estimated breaks in raw and cyclical volatilities. One of the novelties of our analysis is the consideration of those two breakpoints when performing the structural estimation exercise.

We report in Table A-2 the ratio of standard deviations for raw variables and their cyclical component. To facilitate the analysis, we focus on the evolution of the volatility at business cycle frequencies, that is, the volatility of the cyclical component extracted using the HP filter. Let us start by comparing the standard deviation of the cyclical component in the 1970-1984 sample period with that of the 1954-1970 era. The volatility of real variables is, on average, over $50 \%$ greater in the 1970 s and early 1980 s than in the pre-1970 period. The standard deviation of the cyclical component of all of nominal variables and credit spreads more than doubles in the 1970s and early 1980s with respect to the 1950s and 1960s. Finally, financial quantity measures are also more volatile over the second sample period. The more dramatic change is the one experienced by demand deposits at commercial banks whose variability quadruples. 
When comparing the standard deviations of the cyclical component for the post-1984 period with that of the 1970-1984 sample period, we conclude that the volatility of consumption, investment, and output decreases by about 55\%. This slowdown in the volatility of real variables is what is referred to as the Great Moderation. Nominal variables and credit spreads follow the same pattern as real variables. Regarding labor market aggregates, we observe that while the volatility of hours worked is about $36 \%$ smaller, business cycle fluctuations are wider for real average hourly wages. The latter was first documented by Gali and Rens (2010). Champagne and Kurmann (2011) provide further evidence on this empirical fact using micro data. Financial quantity variables are also more volatile in the 1984-2006 sample period. The most significant increases in cyclical variability are the ones for the Wilshire 5000 index whose volatility is over seven times larger than in the 1970s and early 1980s and for checkable deposits whose variability more than doubles. Net worth for the nonfarm business sector and net private savings are $45 \%$ more volatile in the Great Moderation era than in the Great Inflation period. Therefore, we can state that in the post-1984 period there is a dichotomy in the volatility of both financial and labor market variables.

\section{The Model}

Our theoretical framework features real and nominal rigidities as in Smets and Wouters (2007). In order to assess the role played by financial frictions in the evolution of volatilities in the US economy, we extend the framework including financial rigidities as in BGG. Financial frictions arise because there is asymmetric information between borrowers and lenders. Following Townsend's (1979)'s costly state verification framework, we assume that while borrowers freely observe the realization of their idiosyncratic risk, lenders must pay monitoring costs to observe an individual borrower's realized return.

Since Christiano, Motto, and Rostagno (2003) integrated the financial accelerator mechanism of BGG in the workhorse DSGE model, several studies have focused on assessing the empirical relevance of the financial accelerator by comparing the model fit with that of the workhorse DSGE model or on studying the propagation of real and nominal shocks. In this paper, we focus the analysis on two issues: the role of financial shocks and the model's potential to account for breaks in the second moments of the data. We incorporate in the theoretical framework a shock to firms' wealth and a shock to agency costs. While the former has been previously studied, the inclusion of the latter is a major novelty of this paper. 
Our model economy is populated by households, financial intermediaries, entrepreneurs, capital producers, intermediate good firms, retailers, labor packers, and government.

3.1 Retailers: The retail sector is populated by infinitely lived and perfectly competitive firms producing final goods, $Y_{t}$, by combining a continuum of intermediate goods, $Y_{t}(i)$, $i \in[0,1]$, according to a Dixit-Stiglitz aggregator $Y_{t}=\left[\int_{0}^{1}\left(Y_{t}(i)\right)^{\frac{1}{1+\lambda_{t}^{p}}}\right]^{1+\lambda_{t}^{p}}$. The price markup, $\lambda_{t}^{p}$, is assumed to follow the exogenous stochastic process

$$
\ln \left(\lambda_{t}^{p}\right)=\left(1-\rho_{\lambda^{p}}\right) \ln \left(\lambda_{\star}^{p}\right)+\rho_{\lambda^{p}} \ln \left(\lambda_{t-1}^{p}\right)+\varepsilon_{\lambda^{p}, t}, \quad \varepsilon_{\lambda^{p}, t} \sim \mathcal{N}\left(0, \sigma_{\lambda^{p}}\right)
$$

where $\lambda_{\star}^{p}$ stands for the value of the markup at the steady state.

3.2 Intermediate goods sector: There is a continuum of infinitely lived producers of intermediate goods, indexed by $i \in[0,1]$, operating under monopolistic competition. They produce intermediate inputs, $Y_{t}(i)$, combining labor services, $H_{t}$, provided by households and capital services, $k_{t}$, provided by entrepreneurs using a Cobb-Douglas technology.

$$
Y_{t}(i)=\left[Z_{a, t} H_{t}(i)\right]^{1-\alpha} k_{t}(i)^{\alpha}-Z_{a, t} \Phi
$$

where $\Phi$ is a fixed cost of production and $Z_{a, t}$ stands for the neutral technology shock. We assume that $Z_{a, t}$ is such that

$$
Z_{t} \equiv \log \left(\Delta Z_{a, t}\right)=\left(1-\rho_{z}\right) \Upsilon_{z}+\rho_{z} Z_{t-1}+\varepsilon_{Z, t}, \quad \text { with } \quad \epsilon_{Z, t} \sim \mathcal{N}\left(0, \sigma_{Z}\right)
$$

Thus, we assume that the growth rate of the neutral technological progress follows an $\operatorname{AR}(1)$ process where $\Upsilon_{z}$ is the average growth rate of the economy.

Intermediate goods producers face a pricing problem in a sticky price framework à la Calvo. At any given period, a producer is allowed to reoptimize her price with probability $\left(1-\xi_{p}\right)$. We assume that those firms that do not reoptimize their prices set them using the following indexation rule

$$
P_{t}(i)=P_{t-1}(i) \pi_{t-1}^{\iota_{p}} \pi_{\star}^{1-\iota_{p}}
$$

where $\pi \equiv P_{t} / P_{t-1}$ is the gross inflation rate and $\pi_{\star}$ is the inflation rate at the steady state. When reoptimization is possible, an intermediate firm $i$ will set the price $\widetilde{P}_{t}$ that maximizes the expected value of the firm

$$
\mathbb{E}_{t} \sum_{s=0}^{\infty} \xi_{p}^{s} \beta^{s} \frac{\Lambda_{t+s}}{\Lambda_{t}}\left[\widetilde{P}_{t}(i)\left(\prod_{l=1}^{s} \pi_{t+l-1}^{\iota_{p}} \pi_{\star}^{1-\iota_{p}}\right) Y_{t+s}(i)-W_{t+s} H_{t+s}(i)-P_{t+s} r_{t+s}^{k} k_{t+s}(i)\right]
$$


subject to its demand function and to cost minimization. In the above expression, $\Lambda_{t}$ stands for the stochastic discount factor between $t$ and $t+s$ for households, $W_{t}$ is the nominal wage, and $r^{k}$ the real rate paid on capital services.

3.3 Capital producers: They are infinitely lived agents operating in a perfectly competitive market. Capital producers produce new physical capital stock, $K_{t+1}$, using a constant returns to scale technology which combines final goods, $I_{t}$, with currently installed capital, $K_{t}$, which is repurchased to entrepreneurs. The new capital is sold to entrepreneurs at price $P_{t}^{k}$. We assume that one unit of time $\mathrm{t}$ investment delivers $\zeta_{t}$ units of time $t+1$ physical capital. The stochastic process $\zeta_{t}$ is the investment-specific technology shock along the lines of Greenwood, Hercowitz, and Krusell (2000).

$$
\ln \left(\zeta_{t}\right)=\rho_{\zeta, 1} \ln \left(\zeta_{t-1}\right)+\varepsilon_{\zeta, t} \quad \varepsilon_{\zeta, t} \sim \mathcal{N}\left(\sigma_{\zeta}, 1\right)
$$

Following Christensen and Dib (2008), we assume that capital producers are subject to quadratic capital adjustment costs. The representative capital producer chooses the level of investment that maximizes her profits which delivers the following expression for the relative price of capital $Q_{t}=\frac{P_{t}^{k}}{P_{t}}=\frac{1}{\zeta_{t}}\left[1+\xi\left(\frac{I_{t}}{K_{t}}-\left(\mathfrak{Z}_{\star}-1+\delta\right)\right)\right]$, which is the standard Tobin's q equation. In the absence of capital adjustment costs, the relative price for capital, $Q_{t}$, is equal to the inverse of the investment-specific shock. We assume that the aggregate capital stock of the economy evolves according to

$$
K_{t}=(1-\delta) K_{t}+\zeta_{t} I_{t}
$$

3.4 Labor Packers: As in Erceg, Henderson, and Levin (2000), we assume that a representative labor packer or employment agency combines the differentiated labor services provided by households, $H_{t}(i)$, according to $H_{t}=\left[\int_{0}^{1} H_{t}(i)^{\frac{1}{1+\lambda_{t}^{w}}}\right]^{1+\lambda_{t}^{w}}$, where $\lambda_{t}^{w}$ is the wage markup which evolves exogenously as

$$
\ln \left(\lambda_{t}^{w}\right)=\left(1-\rho_{\lambda^{w}}\right) \ln \left(\lambda_{\star}^{w}\right)+\rho_{\lambda^{w}} \ln \left(\lambda_{t-1}^{w}\right)+\varepsilon_{\lambda^{w}, t}, \quad \varepsilon_{\lambda^{w}, t} \sim \mathcal{N}\left(0, \sigma_{\lambda^{w}}\right)
$$

In this setup, a wage markup shock is observationally equivalent to a labor supply shock. Profit maximization by the perfectly competitive labor packers implies the following labor demand function

$$
H_{t}(i)=\left[\frac{W_{t}(i)}{W_{t}}\right]^{-\left(\frac{1+\lambda_{t}^{w}}{\lambda_{t}^{w}}\right)} H_{t}
$$


where $W_{t}(i)$ is the wage received from the labor packer by the type $i$ household.

3.5 Households: We assume there is a continuum of infinitely lived households, each endowed with a specialized type of labor $i \in[0,1]$. Household $i$ solves the following optimization problem:

$$
\mathbb{E}_{t} \sum_{j=0}^{\infty} \beta^{j} b_{t+j}\left[\ln \left(C_{t+j}-h C_{t+j-1}\right)-\theta \frac{H_{t+j}(i)^{1+\nu}}{1+\nu}\right]
$$

subject to

$$
C_{t}+\frac{D_{t+1}}{P_{t}}+\frac{N B_{t+1}}{P_{t}} \leq \frac{W_{t}(i)}{P_{t}} H_{t}(i)+R_{t-1} \frac{D_{t}}{P_{t}}+R_{t-1}^{n} \frac{N B_{t}}{P_{t}}+\text { div }_{t}-T_{t}-\text { Trans }_{t}
$$

where $C_{t}$ stands for consumption, $h$ for the degree of habit formation, $D_{t+1}$ for today's nominal deposits in the financial intermediary, $H_{t}(i)$ for hours worked, $\nu$ for the inverse of the Frisch elasticity of labor, $b_{t}$ for a shock to the stochastic discount factor, $R_{t}$ for the riskfree nominal interest rate paid on deposits, $R_{t}^{n}$ for the risk-free nominal interest rate paid on government bonds, $N B_{t}$ for nominal government bonds, $T_{t}$ for real taxes (subsidies) paid to (received from) the government, div for dividends obtained from ownership of firms, and Trans $_{t}$ for wealth transfers from/to the entrepreneurial sector. The nature of these transfers is described later in this section. Following Erceg, Henderson, and Levin (2000), we assume complete markets which implies that, in equilibrium, all households make the same choice of consumption, deposit holdings, and nominal bond holdings. Hours worked and wages differ across households due to the monopolistic labor supply.

The stochastic discount factor fluctuates endogenously with consumption and exogenously with the intertemporal preferece shock, $b_{t}$, which is given by

$$
\ln \left(b_{t}\right)=\rho_{b} \ln \left(b_{t-1}\right)+\varepsilon_{b, t}, \quad \varepsilon_{b, t} \sim \mathcal{N}\left(0, \sigma_{b}\right)
$$

Households set nominal wages for specialized labor services by means of staggered contracts. In any period $t$, a fraction $\xi_{p}$ of households cannot reoptimize their wages, but follows the indexation rule

$$
W_{t}(i)=W_{t-1}(i)\left(\pi_{t-1} \mathfrak{Z}_{t-1}\right)^{\iota w}\left(\pi_{\star} \mathfrak{Z}_{\star}\right)^{1-\iota w}
$$

A fraction $\left(1-\xi_{w}\right)$ of households are allowed to choose an optimal nominal wage $\bar{W}_{t}(i)$, by 
solving

$$
\max \mathbb{E}_{t} \sum_{s=0}^{\infty} \xi_{w}^{s} \beta^{s}\left[-b_{t+s} \theta \frac{H_{t+s}(i)^{1+\nu}}{1+\nu}+\Lambda_{t+s} W_{t}(j) H_{t+s}(j)\right]
$$

subject to the labor demand function.

3.6 Entrepreneurs and financial intermediaries: Entrepreneurs are finitely lived risk-neutral agents who borrow funds captured by financial intermediaries from households. Conditional on survival, an entrepreneur $j$ purchases physical capital, $K_{t+1}^{j}$, at relative price $Q_{t}$. At the beginning of the period, an entrepreneur is hit by an idiosyncratic shock, $\omega_{t}^{j}$, that affects the productivity of her capital holdings. This idiosyncratic shock is at the center of the informational asymmetry, since it is only freely observed by the entrepreneur. For tractability purposes, we assume $\omega_{t}^{j}$, for all $j$, is $i . i . d$ lognormal with c.d.f. $F(\omega)$, parameters $\mu_{\omega}$ and $\sigma_{\omega}$, such that $\mathbb{E}\left[\omega^{j}\right]=1$. After observing the realization of the idiosyncratic shock, entrepreneurs choose the capital utilization rate, $u_{t}^{j}$, that solves the following optimization problem

$$
\max _{u_{t}^{j}}\left[u_{t}^{j} r_{t}^{k, j}-a\left(u_{t}^{j}\right)\right] \omega_{t}^{j} K_{t}^{j}
$$

where, around the steady state, $a(\cdot)=0, a^{\prime}(\cdot)>0, a^{\prime \prime}(\cdot)>0$ and $u^{\star}=1$. Therefore, capital services, $k_{t}^{j}$, rented to intermediate goods producers are given by $k_{t}^{j}=u_{t}^{j} \omega_{t}^{j} K_{t}^{j}$.

The capital demand for entrepreneur $j$ is given by the gross nominal returns on holding one unit of capital from $t$ to $t+1$

$$
R_{t+1}^{k, j}=\left[\frac{r_{t+1}^{k, j} u_{t+1}^{j}+\omega_{t+1}^{j}(1-\delta) Q_{t+1}}{Q_{t}}\right] \frac{P_{t+1}}{P_{t}}
$$

where $\omega_{t+1}^{j}(1-\delta) Q_{t+1}$ is the return to selling the undepreciated capital stock back to capital producers.

An entrepreneur can finance the purchasing of new physical capital investing her own net worth, $N_{t+1}^{j}$, and using external financing (in nominal terms), $B_{t+1}^{j}$, to leverage her project. Given that the entrepreneur is risk neutral, she offers a debt contract that ensures the lender a return free of aggregate risk. The lender can diversify idiosyncratic risks by holding a perfectly diversified portfolio which allows her to offer a risk-free rate on deposits to households. Financial intermediaries cannot observe the realized return of a borrower unless they pay an auditing cost. To minimize costs, lenders will audit borrowers only when they 
report their inability to pay the loan back under the terms of the contract. A debt contract is characterized by a triplet consisting of the amount of the loan, $B_{t+1}^{j}$, the contractual rate, $Z_{t+1}^{j}$, and a schedule of state-contingent threshold values of the idiosyncratic shock, $\bar{\omega}_{n, t+1}^{j}$, where $n$ refers to the state of nature. For values of the idiosyncratic productivity shock above the threshold, the entrepreneur is able to repay the lender at the contractual rate. For values below the threshold, the borrower defaults, and the lender steps in and seizes the firm's assets. A fraction of the realized entrepreneurial revenue, $\mu$, is lost in the process of liquidating the firm. In this case, the financial intermediary obtains

$$
\left(1-\mu_{t+1}\right) P_{t} \omega_{n, t+1}^{j} R_{n, t+1}^{k} Q_{t} K_{t+1}^{j}
$$

where $\mu_{t+1}$ stands for the marginal bankruptcy cost. In the literature, the marginal bankruptcy cost is assumed to be a constant parameter. We assume, however, that it is a drifting parameter so that exogenous changes in the level of financial rigidities affect the business cycle properties of the model. Later in this section, we describe in detail the relevance of this assumption and the stochastic specification chosen.

The terms of the debt contract are chosen to maximize expected entrepreneurial profits conditional on the return of the lender, for each possible state of nature, being equal to the riskless rate. That is, the participation constraint is given by the zero profit condition for the financial intermediary from which we can derive the supply for loans

$$
\mathbb{E}_{t} \frac{R_{t+1}^{k}}{R_{t}}\left[\Gamma\left(\bar{\omega}_{t+1}\right)-\mu_{t+1} G\left(\bar{\omega}_{t+1}\right)\right]=\left(\frac{Q_{t} K_{t+1}-N_{t+1}}{Q_{t} K_{t+1}}\right)
$$

where $\Gamma\left(\bar{\omega}_{t+1}^{j}\right)=\int_{0}^{\bar{\omega}_{t+1}^{j}} \omega f(\omega) d \omega+\bar{\omega}_{t} \int_{\bar{\omega}_{t+1}^{j}}^{\infty} f(\omega) d \omega$ is the expected share of gross entrepreneurial earnings going to the lender, and $\mu_{t+1} G\left(\bar{\omega}_{t+1}^{j}\right)=\mu_{t+1} \int_{0}^{\bar{\omega}_{t+1}^{j}} \omega f(\omega) d \omega$ are the expected monitoring costs. The above states that financial intermediaries are only willing to provide funds to entrepreneurs if they are compensated by the default risk. That is, lenders charge a premium over the risk free rate, the so-called external finance premium, $\mathbb{E}\left[\frac{R_{t+1}^{k}}{R_{t}}\right]$. Equation (17) provides one of the foundations of the financial accelerator mechanism: a linkage between the entrepreneur's financial position and the cost of external funds, which ultimately affects the demand for capital.

The external finance premium is determined by two channels: the balance-sheet channel, through the debt-to-assets ratio, and the information channel, through the elasticity of the external finance premium with respect to the leverage ratio. The external finance premium 
is the key relationship of the financial accelerator, since it determines the efficiency of the contractual relationship between borrowers and lenders. We enrich the theoretical framework by assuming that this essential mechanism is affected exogenously by two financial shocks: a wealth shock and a shock to the marginal bankruptcy cost.

The balance-sheet channel states the negative dependence of the premium on the amount of collateralized net worth, $N_{t+1}$. The higher the stake of a borrower in the project, the lower the premium over the risk-free rate required by the intermediary. We introduce shocks to this channel through an entrepreneurial equity shifter. These types of wealth shocks were first introduced by Gilchrist and Leahy (2002). Recently, they have been explored by Christiano, Motto, and Rostagno (2010), Nolan and Thoenissen (2009), and Gilchrist, Ortiz, and Zakrajs̆ek (2009).

Recently, Dib (2009) has explored shocks to the elasticity of the risk premium with respect to the entrepreneurial leverage ratio. He solves the model discarding the contribution of the dynamics of the idiosyncratic productivity threshold to the dynamics of the remaining variables. ${ }^{3}$ Hence, those shocks can refer to shocks to the standard deviation of the entrepreneurial distribution, to agency costs paid by financial intermediaries to monitor entrepreneurs, and/or to the entrepreneurial default threshold. He cannot, however, discriminate among the sources of the shock. Christiano, Motto, and Rostagno (2010) solve the model completely so that they can introduce a specific type of shock affecting the efficiency of the lending activity. In particular, they propose riskiness shocks affecting the standard deviation of the entrepreneurial distribution. A positive shock to the volatility of the idiosyncratic productivity shock widens the distribution so that financial intermediaries find it more difficult to distinguish the quality of entrepreneurs.

We introduce exogenous disturbances affecting the elasticity of the premium with respect to the leverage ratio by assuming the marginal bankruptcy cost is time-variant. The information channel, therefore, establishes that the external finance premium is a positive function of the severity of the agency problem measured by the marginal bankruptcy cost, $\mu_{t}$. An increase in the level of financial rigidity implies an enlargement of the informational asymmetry rents which translates into a higher premium on external funds. To the best of our knowledge, only Levin, Natalucci, and Zakrajšek (2004) have explored time variation along this margin. They estimate a partial equilibrium version of the BGG model using a panel of 900 US nonfinancial firms over the period 1997:1 to 2003:3. They find evidence of

\footnotetext{
${ }^{3} \mathrm{BGG}$ perform simulation exercises under a parameterization that implied a negligible contribution of the dynamics of the cutoff. However, most of the contributions to the financial accelerator literature have adopted this result as a feature of the model. Therefore, they proceed by setting those dynamics to zero.
} 
significant time variation in the marginal bankruptcy cost. In particular, they conclude that time variation in the parameter of interest is the main driver of the swings in the modelimplied external finance premium. We assume that the shock to the marginal bankruptcy cost follows

$$
\ln \left(\mu_{t}\right)=\left(1-\rho_{\mu}\right) \ln \left(\mu^{\star}\right)+\rho_{\mu} \ln \left(\mu_{t-1}\right)+\varepsilon_{\mu, t}, \quad \varepsilon_{\mu, t} \sim \mathcal{N}\left(0, \sigma_{\mu}\right)
$$

The unconditional mean of the process governing the agency problem between borrowers and lenders, $\mu^{\star}$, determines the average level of financial rigidity in the model economy. This parameter governs, then, the size of the financial accelerator. In particular, $\mu^{\star}$ stands for the steady-state level of the marginal bankruptcy cost.

In the estimation exercise, we consider as an additional parameter the unconditional mean of the external finance premium. Note that both the unconditional mean of the premium and of the size of the financial accelerator completely describe the characteristics of the financial sector in the model economy at the steady state. On the one hand, a larger average marginal bankruptcy cost translates into a harder access to external financing. On the other hand, a higher average for the external finance premium implies that, on average, external financing is more expensive. Therefore, the flexibility of the financial system at the steady state in the model economy is a negative function of the unconditional means for the marginal bankruptcy cost and the external finance premium.

The other main component of the financial accelerator is the evolution of entrepreneurial wealth. Note that the return on capital and, hence, the demand for capital by entrepreneurs depend on the dynamics of net worth. Let $V_{t}$ be entrepreneurial equity and $W_{t}^{e}$ be the wealth transfers made by exiting firms to the pool of active firms. Then, aggregate entrepreneurial net worth (average net worth across entrepreneurs) is given by the following differential equation

$$
\begin{aligned}
P_{t} N_{t+1} & =x_{t} \gamma V_{t}+P_{t} W_{t}^{e} \\
& =x_{t} \gamma\left[P_{t-1} R_{t}^{k} Q_{t-1} K_{t}-R_{t-1} B_{t}-\mu_{t} G\left(\bar{\omega}_{t}\right) P_{t-1} R_{t}^{k} Q_{t-1} K_{t}\right]+P_{t} W_{t}^{e}
\end{aligned}
$$

where $\gamma$ is the survival probability, $\left[R_{t}^{k} P_{t-1} Q_{t-1} K_{t}^{j}-R_{t-1} B_{t}\right]$ is the nominal gross return on capital net of repayment of loans in the nondefault case, $\mu_{t} G\left(\bar{\omega}_{t}\right) R_{t}^{k} Q_{t-1} K_{t}$ is the gross return lost in case of bankruptcy, and $x_{t}$ is the wealth shock which assumed to be

$$
\ln \left(x_{t}\right)=\rho_{x} \ln \left(x_{t-1}\right)+\varepsilon_{x, t}, \quad \varepsilon_{x, t} \sim \mathcal{N}\left(0, \sigma_{x}\right),
$$


Wealth shocks can be interpreted as shocks to the stock market that generate asset price movements that cannot be accounted for by fundamentals. Christiano, Motto, and Rostagno (2003) suggest that shocks to entrepreneurial wealth capture the so-called irrational exuberance. We can also consider wealth shocks as a reduced form for changes in fiscal policy that have redistributive effects between firms and households. Exogenously driven changes in the valuation of entrepreneurial equity need to be financed by another sector of our model economy. We assume that the household sector receives (provides) wealth transfers from (to) the entrepreneurial sector, which are defined as

$$
\operatorname{Trans}_{t}=N_{t+1}-\gamma V_{t}-W_{t}^{e}=\gamma V_{t}\left(x_{t}-1\right)
$$

where $\gamma V_{t}+W_{t}^{e}$ is the value that entrepreneurial equity would have taken if there were no wealth shocks.

3.7 Government: Government spending is financed by government nominal bonds sold to households and by lump-sum taxes.

$$
N B_{t+1}+P_{t} T_{t}=P_{t} G_{t}+R_{t-1}^{n} N B_{t}
$$

where the process for public spending $G_{t}$ is given by $G_{t}=\left(1-\frac{1}{g_{t}}\right) Y_{t}$, where the government spending shock, $g_{t}$, follows the stochastic process

$$
\ln g_{t}=\left(1-\rho_{g}\right) \ln g+\rho_{g} \ln g_{t-1}+\varepsilon_{g, t}, \quad \varepsilon_{g, t} \sim \mathcal{N}\left(0, \sigma_{g}\right)
$$

The monetary authority follows a Taylor-type interest rate rule. We assume the authority adjusts the short-term nominal interest rate responding to deviations of inflation and output growth from the target, i.e., their steady-state values.

$$
\left(\frac{R_{t}^{n}}{R^{n \star}}\right)=\left(\frac{R_{t-1}^{n}}{R^{n \star}}\right)^{\rho_{R}}\left(\frac{\pi_{t}}{\pi^{\star}}\right)^{\left(1-\rho_{R}\right) \psi_{\pi}}\left(\frac{\Delta Y_{t}}{\Upsilon_{z}}\right)^{\left(1-\rho_{R}\right) \psi_{y}} e^{\varepsilon_{R, t}}
$$

with $\rho_{R}>0,\left(1-\rho_{R}\right) \psi_{\pi}>0,\left(1-\rho_{R}\right) \psi_{y}>0$, and $\varepsilon_{R, t} \sim \mathcal{N}\left(0, \sigma_{R}\right)$.

3.8 Market Clearing: The final goods market clearing condition (total resources constraint)

$$
Y_{t}=C_{t}+I_{t}+G_{t}+a\left(u_{t}\right) K_{t}+\mu_{t} G\left(\bar{\omega}_{t}\right) R_{t}^{k} Q_{t-1} K_{t}
$$


and the credit market clearing condition

$$
\frac{D_{t+1}}{P_{t}}=\frac{B_{t+1}}{P_{t}}=Q_{t} K_{t+1}-N_{t+1}
$$

\section{Bayesian Inference}

4.1 Data: We estimate the model with Bayesian estimation techniques using nine macroeconomic quarterly US time series as observable variables: the growth rate of real per capita net worth in the nonfarm business sector, the growth rate of real per capita gross value added (GVA) by the nonfarm business sector, the growth rate of real per capita consumption defined as nondurable consumption and services, the growth rate of real per capita investment defined as gross private investment, the growth rate of real hourly wage in the nonfarm business sector, log hours worked, the log difference of the GVA deflator, the federal funds rate, and the spread between the Baa corporate bond rate and the federal funds rate. A complete description of the data set is given in the online appendix. The model is estimated over the full sample period from 1954.4 to 2006.4.

All the series enumerated above except net worth in the nonfarm business sector and the credit spread are standard in the data sets used in the empirical macro literature. We discuss in further detail the inclusion of such financial variables in our set of observable variables. Our theoretical framework describes the evolution of three financial series: entrepreneurial wealth, debt, and the external finance premium. Therefore, the estimation exercise could aim to match the behavior of all of those. However, the informational content of debt is already included in the series for net worth by definition. Net worth for a firm is generally defined as total assets minus total liabilities. However, in order to be consistent with the model, we define net worth as tangible assets minus credit market liabilities. First, the model is a model of tangible assets purchased by firms so that it has nothing to say about financial assets held by entrepreneurs. Second, external financing in the model relates only to that obtained in credit markets. Hence, we do not consider trade and taxes payable nor miscellaneous liabilities provided in the Flow of Funds Accounts. An alternative measure for entrepreneurial wealth used by Christiano, Motto, and Rostagno (2010) is stock market data. In particular, they use the Wilshire 5000 index. This measure contains information only for publicly traded firms, which are a smaller set of firms than the one linked to the aggregate macroeconomic variables of our data set. Moreover, this series is only available 
from 1971 which makes it unattractive to study the Great Inflation period in comparison to the 1950s-1960s.

In order to proxy the external finance premium, BGG suggest considering the spread between the prime lending rate and the 6-month Treasury bill rate. Christiano, Motto, and Rostagno (2003) define the external finance premium as the premium on the US industrial Baa corporate bond over the federal funds rate and Christiano, Motto, and Rostagno (2010) use the US Industrial Bbb corporate bond yield, backcasted using Baa corporate bond yields, minus the federal funds rate. Recently, Gilchrist, Ortiz, and Zakrajšek (2009) use as proxy for the external finance premium a corporate credit spread index constructed using individual security-level data. We proceed by defining our proxy for the external finance premium as the spread between the US industrial Baa corporate bond yields and the federal funds rate since, conceptually, it is the closest measure to the model implied external finance premium.

4.2 Structural Breaks: We aim to test the relative role played by three theories in accounting for the observed breaks in volatilities: luck, the conduct of monetary policy, and financial institutions. To do so, we allow for breaks in three subsets of parameters: size of shocks, monetary policy coefficients, and parameters characterizing the financial system which are the unconditional means of the marginal bankruptcy cost and the external finance premium. We perform our estimation exercise by using the full sample information to estimate the parameters that are constant across subsamples and the corresponding subsample information to estimate those parameters that are subject to structural breaks. We use a relatively naïve approach in treating structural breaks. We assume economic agents do not face an inference problem to learn endogenously about the regimes. When forming rational expectations about the dynamic economy, they take regime changes as completely exogenous events and assume that the current regime will last forever. Thus, once a structural break in parameters happens, agents learn about it immediately and conveniently readjust their choices. This simplifying assumption facilitates the estimation when, as in our case, breaks in the steady state of the economy are allowed. However, the econometrician must make sure she is using the same information set as the economic agent when conducting the estimation exercise. In the remaining of this section, we provide an overview of the approach taken in the estimation of the model.

Let $\varrho$ be the subvector of structural parameters that is constant across subsamples and $\tau$ be the subvector subject to structural breaks. The system of log-linearized equilibrium 
conditions $^{4}$ can be represented as

$$
\Gamma_{0}(\varrho, \tau) \widetilde{s}_{t}=\Gamma_{1}(\varrho, \tau) \widetilde{s}_{t-1}+\Psi(\varrho, \tau) \varepsilon_{t}+\Pi(\varrho, \tau) \eta_{t}
$$

where $\widetilde{s}_{t}$ is a vector of model variables expressed in deviations from steady state, $\varepsilon_{t}$ is a vector of exogenous shocks, and $\eta_{t}$ is a vector of rational expectations errors with elements $\eta_{t}^{x}=\widetilde{x}_{t}-\mathbb{E}_{t-1}\left[\widetilde{x}_{t}\right]$. Given that our system is linear and we have assumed that $\varepsilon_{t} \sim \mathcal{N}(0, \Sigma)$, we can evaluate the likelihood function using the Kalman filter. We deviate from the standard approach in the literature by casting the solution to the LRE model in state space form for the variables in log-levels instead of in log-deviations from the steady state.

$$
\begin{aligned}
\text { Transition equations : } & s_{t}=[I-\Phi(\varrho, \tau)] \bar{s}+\Phi(\varrho, \tau) s_{t-1}+\Phi_{\varepsilon}(\varrho, \tau) \varepsilon_{t} \\
\text { Measurement equations : } & y_{t}=B(\varrho, \tau) s_{t}
\end{aligned}
$$

where $s_{t}$ is the state vector in log-levels, that is, $s_{t}=\widetilde{s}_{t}+\bar{s}$, and $\bar{s}$ is the log of the state vector evaluated in the steady state.

From the above, it is obvious that structural breaks in any parameter affect the system matrices of the filter. The Kalman filter is a very flexible environment which can accommodate any of these modifications. But the econometrician must handle with special care breaks in parameters that affect the steady state of the economy since she has to take into account the change in the information set used by economic agents. Note that while breaks in the size of shocks shift only $\Phi_{\varepsilon}(\varrho, \tau)$ and breaks in monetary policy coefficients affect $\Phi(\varrho, \tau)$, breaks in parameters defining the steady state of the economy translate into changes in $\Phi(\varrho, \tau)$ and $\bar{s}$. In our analysis, we are allowing for structural breaks in two parameters governing the steady state of the economy: the unconditional mean of the marginal bankruptcy cost and the steady state value of the external finance premium. We propose the following modification of the forecasting step in the Kalman filter to accommodate for breaks in the steady state of the economy. Suppose that at $t=t^{\star}$, the steady state of the economy shifts from $\bar{s}_{1}$ to $\bar{s}_{2}$. Then, for $t<t^{\star}$, the forecasting of the states is given by $\widehat{s}_{t \mid t-1}=\left[I-\Phi\left(\varrho, \tau_{1}\right)\right] \bar{s}_{1}+\Phi\left(\varrho, \tau_{1}\right) \widehat{s}_{t-1 \mid t-1}$. At $t=t^{\star}$, we have $\widehat{s}_{t \mid t-1}=\left[I-\Phi\left(\varrho, \tau_{2}\right)\right] \bar{s}_{2}+\Phi\left(\varrho, \tau_{2}\right)\left[\bar{s}_{2}-\bar{s}_{1}\right]+\Phi\left(\varrho, \tau_{2}\right) \widehat{s}_{t-1 \mid t-1}$. If $t>t^{\star}$, then $\widehat{s}_{t \mid t-1}=\left[I-\Phi\left(\varrho, \tau_{2}\right)\right] \bar{s}_{2}+\Phi\left(\varrho, \tau_{2}\right) \widehat{s}_{t-1 \mid t-1}$.

4.3 Prior distribution: The prior information on the parameters used in the estimation exercise is available in the first three columns of Table A-4 and Table A-5. Our choices for standard parameters are along the lines of the recent literature. There have been few

\footnotetext{
${ }^{4}$ The log-linearized system is available in the online Appendix.
} 
attempts, however, of estimating the parameters governing the financial accelerator. Thus, we provide here a description of our prior for those parameters. Regarding the subvector of parameters subject to structural breaks, we assume identical priors across subsamples.

The parameters governing the financial accelerator are the default probability, $F(\bar{\omega})$, the variance of the idiosyncratic productivity shock, $\sigma_{\omega}^{2}$, the survival probability, $\gamma$, the unconditional mean of the marginal bankruptcy cost, $\mu_{\star}$, the external finance premium at the steady state, $R_{\star}^{k} / R_{\star}$, and the size of financial shocks. Following the literature, we use degenerate priors for the default probability and the size of the idiosyncratic productivity shock. In particular, we set $F(\bar{\omega})$ equal to the average of the historical default rates for US bonds over the period 1971-2005 reported by Altman and Pasternack (2006). We fix the idiosyncratic productivity variance equal to 0.24 .

We choose a Beta distribution for the survival probability, $\gamma$. The location parameter is chosen by solving the steady state for the financial sector when the debt-to-wealth ratio is equal to its historical average. Moreover, the location parameter value implies that firms live, on average, 17 years. This tenure is close to the median tenure reported by Levin, Natalucci, and Zakrajšek (2004) from a panel of 900 nonfinancial firms. The prior distribution for the unconditional mean of the external finance premium, $R_{\star}^{k} / R_{\star}$, is Gaussian with location parameter equal to the sample average.

Regarding the steady state value of the marginal bankruptcy cost, $\mu^{\star}$, to the best of our knowledge, there has not been an attempt to estimate such parameter using aggregate data. We use a Beta distribution for this parameter since it must lie inside the unit interval. In order to determine the location parameter of the beta prior distribution, we consider micro evidence on bankruptcy costs. Altman (1984), using data from 26 firms, concludes that bankruptcy costs are about $20 \%$ of the firm's value prior to bankruptcy and in the range $11-17 \%$ of firm's value up to three years prior to bankruptcy. Alderson and Betker (1995) analyze 201 firms that completed Chapter 11 bankruptcies during the period 1982-1993 to determine that the mean liquidation costs are 36.5\%. Using those two results, Carlstrom and Fuerst (1997) conclude that the interval empirically relevant for the marginal bankruptcy cost parameter is [0.20,0.37]. Levin, Natalucci, and Zakrajšsek (2004) estimate a partial equilibrium version of the model by BGG using panel data over the period 1997 to 2003. As a byproduct of their estimation, they obtain the model implied time series for the marginal bankruptcy cost. Their estimates lie in the range of $7 \%$ to $45 \%$. Therefore, we assume the beta distribution for the unconditional average level of financial rigidity is centered at 0.28. We choose the diffusion parameter to be equal to 0.05 so that the $95 \%$ credible set 
encompasses most of the values provided in the literature.

4.4 Posterior estimates of the parameters: The last two columns of Tables A-4 and A-5 report the posterior median and the $95 \%$ credible intervals of a chain of 500,000 posterior draws with a burn-in period of $20 \%$. We first analyze Table A-4, which contains those parameters not allowed to change over time. The survival probability of entrepreneurs is estimated to be about $98 \%$ per quarter which implies a median life for entrepreneurs of about 12 years. The estimated degree of price and wage stickiness is relatively small. In particular, the Calvo parameter for prices is $51 \%$ and for wages only $8 \%$. These results are due to the fact that the amplification and propagation mechanism usually captured by nominal rigidities is taken care off by the financial rigidity embedded in the model.

Table A-5 reports the estimates for those parameters allowed to change in 1970:Q1 and 1984:Q2. First, we analyze the estimated breaks in the parameters governing the conduct of monetary policy. As pointed out elsewhere in the literature, the response of the monetary authority to inflation is looser in the 1970s than during the Great Moderation. The conduct of monetary policy during Burns-Miller mandate only differed from Martin's recipes in the response to deviations of output growth from the objective. In particular, while the response to inflation does not change significantly in the 1970s, the response to real outcomes was over $75 \%$ tighter than in the 1950s-1960s. During Volcker-Greenspan period, the response to output growth is identical to the one during the Great Inflation, but the response to inflation is almost $20 \%$ tighter. We can conclude that, relatively speaking, during the 1970s, the monetary authority put more emphasis on responding to the real side of the economy than to deviations in the nominal side. Such a trend was reverted by Volcker during the 1980s.

Second, we consider the two parameters characterizing the conditions of access to credit. The steady state value of the external finance premium has been increasing over time which implies that external credit has become more expensive over the last 50 years. In particular, the estimated model implied increase in the unconditional mean of the cost of external financing is $60 \%$ in the 1970 s. Such cost more than triples during the Great Moderation.

These increases in the cost of external financing have been paired up with a higher level of financial rigidity during the Great Inflation and an almost frictionless financial framework since the mid 1980s. The unconditional mean of the marginal bankruptcy cost, which accounts for the easiness of the access to external financing, is $40 \%$ larger in the 1970 s. While in the 1950s-1960s financial intermediaries were able to recover $83 \%$ of the value of the firm in the event of bankruptcy, they recovered only $76 \%$ of the value after liquidation in the 
1970s. The enlargement of the marginal bankruptcy cost may be related to the additional difficulty of extracting information about borrowers in periods of turbulence in the aggregate economy. For the Great Moderation period, the estimated average marginal bankruptcy cost is equal to $5 \%$ which implies a recovery value of $95 \%$. Thus, on average, the most recent period is characterized by an almost frictionless financial environment. The reduction in the average level of financial rigidities accounts not only for the decrease in bankruptcy costs linked to the Bankruptcy Reform Act of 1978 (see White, 1983) but also for other changes in the US financial system. The decades under analysis are characterized by the IT revolution, waves of regulation and deregulation, development of new products, and improvements in the assessment of risk. All these factors define the level of financial rigidity in terms of the model economy. The contemporaneous reduction in the average level of financial rigidity and increase in the unconditional mean of the credit spread are reconcilable under the premise that the former translates into an enlargement of the pool of borrowers, that is, more entrepreneurs in the tails of the distribution are able to leverage up their investments. Consequently, financial entrepreneurs request a higher average premium to compensate for the larger average default risk undertaken when signing a debt contract.

Finally, we describe the estimated breaks for the size of exogenous shocks. The size of financial shocks has increased over time which implies a higher exposure to financial risk in the model economy. On the one hand, the size of the wealth shock is $25 \%$ larger in the 1970s and it increases an additional 91\% during the Great Moderation. Larger balance-sheet shocks affecting the model economy reflect the increasing sensitivity of the system to asset price movements. Note that the US data have been characterized by several price "bubbles" over the last few decades: the dramatic rise in US stock prices during the late 1990s or the housing bubble during the early 2000s, for example. On the other hand, the size of the shock to the marginal bankruptcy cost increases by $43 \%$ in the 1970 s and by $76 \%$ in the mid 1980s. Thus, given that $\mu_{\star}$ is smaller over time, we have that the unconditional average of the process governing the level of financial rigidity is smaller but the variability of the disturbance to the process is larger. We can reconcile these two results by noting that a reduction in $\mu^{\star}$ increases the average recovery rate for financial intermediaries. Hence, intermediaries are willing to enlarge their exposure to risk, which is captured by the increase in $\sigma_{\mu}$.

The size of the remaining shocks but the neutral technology and the government spending shocks increases in the 1970s and decreases in the mid 1980s. In particular, during the Great Inflation, the size of the investment-specific technology shock increases by $27 \%$, that of the 
price and wage markup shocks by $40 \%$ and $37 \%$ respectively, the size of the intertemporal preference shock is $77 \%$ larger and that of the monetary policy shock more than triples. The size of all non-financial shocks decreases during the Great Moderation by a minimum of $18 \%$ as the investment-specific technology shock and a maximum of $67 \%$ as the monetary policy shock. It is also remarkable that the size of the investment-specific, price markup, and monetary policy shock in the post-1984 period is similar to that in the pre-1970.

4.5 Model evaluation: We study the model fit of the data performing posterior predictive checks. We focus on analyzing the performance of the model at replicating the observed swings in cyclical volatility. To do so, we generate samples of 200 observations (after a burn-in period of 1000 observations) from the model economy using every 5000th posterior draw from our sampler. We HP filter the data in log-levels obtained from the simulation and compute the standard deviation of the cyclical component. Table A-3 reports the model-implied ratios of volatilities for the cyclical component. In particular, we report the median and 90\% credible intervals which are due to both parameter and small-sample uncertainty. Given that likelihood function based estimation operates by trying to match the entire autocovariance function of the data, there is a tension between matching standard deviations and other second moments of the data. Therefore, the researcher should not expect a perfect accounting of the observed volatilities. Moreover, in the estimation exercise, we use data in log-levels and first differences instead of cyclical data.

The model successfully generates an enlargement of cyclical volatility for all variables during the Great Inflation. The simulated economy replicates the observed discrepancy in the relative size of the immoderation of nominal and financial price variables with respect to the remaining variables. Our theoretical framework also delivers the differences in size of the slowdown in the volatility of real variables, hours worked, nominal outcomes, and the credit spread. However, while the magnitude of the moderation in real variables and hours worked is smaller than the observed one, the model implied slowdown for nominal variables and financial price variables is larger than that in the data. Our posterior predictive check is successful at generating the divergent patterns in volatility for financial quantity and price measures. While the volatility of credit spread is over $60 \%$ smaller during the Great Moderation, the cyclical volatility of net worth is about $30 \%$ larger.

Conversely to the empirical evidence, the model implies a slowdown in the cyclical volatility of wages during the Great Moderation. We can conclude that changes in the size of shocks, in the conduct of monetary policy, and in the structure of the financial system are not enough to deliver the observed dichotomy in cyclical volatility for labor market aggregates. Gali and 
Rens (2010) and Champagne and Kurmann (2011) state that such a divergent pattern in volatility can be accounted for by a decline in labor market frictions. A more elaborated modeling of the labor market including, for example, search frictions is beyond the scope of this paper.

Given that the model is able to replicate to a large extent the empirical evidence at hand, we conclude that the model proposed in this paper is a good candidate for analyzing the US business cycle properties for real, nominal, and financial variables. The shortcoming of this model is that while it is able to deliver the swings in volatility for hours worked, it cannot generate the divergent pattern for real hourly wages.

\section{Assessing the Drivers of the Financial Immoderation and the Great Moderation}

In this section, we analyze the contribution to the model-implied changes in business cycle properties of each of the potential candidates . To do so, we perform two sets of counterfactual exercises. In Counterfactuals 1-8, we explore the sources of the Great Inflation. We analyze the model drivers of the Great Moderation and the dichotomy in the volatility of financial variables in Counterfactuals 9-16. In Counterfactuals 1 and 9, we analyze the role played by the estimated changes in the response of the monetary authority to deviations of inflation and output growth from the target. We study the relative importance of changes in the unconditional mean for the marginal bankruptcy cost in Counterfactuals 2 and 10. Counterfactuals 3 and 11 report the role played by the estimated breaks in the steady state value for the external finance premium. We assess how relevant are changes in the financial system by simulating the model economy when both the unconditional mean of the level of financial rigidity and of the external finance premium change across sub-samples in Counterfactuals 4 and 12. We determine how relevant are changes in both financial institutions and the monetary policy stance in Counterfactuals 5 and 13 and how relevant is the luck hypothesis in Counterfactuals 6 and 14. We establish the relative role played by only financial shocks in Counterfactuals 7 and 15 and by the remaining shocks in Counterfactuals 8 and 16 .

For illustration purposes, let us consider Counterfactual 1. We proceed by performing 100 simulations for each 5000th draw in the posterior simulator using the following procedure: 
1. Simulate the model economy for 200 periods (after a burn-in of 1000 observations) using the parameter vector characterizing the 1954-1970 sample period. Obtain the cyclical component.

2. Simulate the model economy for 200 periods (after a burn-in of 1000 observations) using the parameter vector characterizing the 1970-1984 sample period. Obtain the cyclical component.

3. Compute the ratio of standard deviations.

4. Simulate the model economy for 200 periods (after a burn-in of 1000 observations) using the parameter vector characterizing the 1954-1970 period but with the monetary policy coefficients of the 1970-1984 parameter vector. Obtain the cyclical component.

5. Compute the ratio of standard deviations with respect to those obtained in step 1.

6. Compute the percentage of the ratio obtained in step 3 attributable to the counterfactual.

Table A-6 reports the percentage of the total increase or decrease in the cyclical standard deviation generated by the model that can be accounted for by the corresponding counterfactual. In Counterfactual 1, we analyze the role played by the estimated changes in 1970 in the response of the monetary authority to deviations of inflation and output growth from the target. The estimated slight loosening of the response to inflation and the tightening in the response to output account for the following percentages of the model-implied increase in cyclical volatility: $17 \%$ for inflation and a $7 \%$ on average for the nominal interest rate, net worth, wages, and consumption.

Counterfactual 2 shows that the estimated $40 \%$ increase in the level of financial rigidity accounts for an average of $16 \%$ of the model-implied increase in the volatility of the cyclical component of output, investment, consumption, hours, interest rate, net worth, and finance premium. It accounts only for $7 \%$ of the increase in inflation volatility and $3 \%$ of that in wage variability. From Counterfactual 3 we conclude that the estimated increase in the external finance premium accounts for $6 \%$ of the model implied immoderation for investment and net worth but it implies a slowdown in the cyclical volatility of the remaining variables. Therefore, as compiled in Counterfactual 4, the relative role played by changes in financial institutions in the Great Inflation is relegated to account for $20 \%$ of the model-implied immoderation in investment and financial variables, $13 \%$ of that in the nominal interest rate, and less than $5 \%$ for the remaining variables. 
Comparing the rows for Counterfactuals 5 and 6 we conclude that the Great Inflation was mostly due to bad luck. While the institutional change is needed to replicate the modelimplied increase in the volatility of nominal variables, financial variables, and investment, it only accounts for about $20 \%$ of the model implied increase in variability. The remaining $80 \%$ is accounted for the larger shocks hitting in the US economy during the 1970s. The immoderation in output, consumption, wages, and hours worked can only be explained by the estimated change in the size of exogenous shocks. The conclusion is quite different when analyzing the main source of the Great Moderation. Counterfactuals 13 and 14 show that the slowdown in cyclical volatility characterizing the post-1984 period cannot be explained by our model without the estimated institutional changes. The combined increase in the size of financial shocks and reduction in the size of the remaining shocks can only account for $22 \%$ of the smoothing in inflation volatility and generate an immoderation in business wealth twice as large as the one needed. The effect in the remaining variables is at odds with the observed evolution of cyclical volatility. The estimated institutional changes, however, account for about $40 \%$ of the model implied moderation in output, hours worked, and inflation; $55 \%$ of the reduction in investment volatility; $25 \%$ of that in consumption; and $78 \%$ of the smoothing of interest rate variability. The new institutional framework overestimates the moderation of credit spreads by about 20\%. Counterfactuals 9 and 12 state that the role of the tightening the response to inflation is only remarkable to account for the moderation in inflation. In particular, it delivers almost 30\% of the model implied slowdown. The estimated reduction in the average level of financial rigidity accounts for most of the role played by the institutional change. However, from Counterfactuals 3 and 11, we conclude that an increase in the average external finance premium generates a reduction in the cyclical volatility of all variables but investment and hourly wage. It also translates into an increase in the cyclical volatility of business wealth of about $7 \%$.

\section{Economic Implications}

6.1 Variance decomposition: Table A-7 provides the variance decomposition at business cycle frequencies. We compute the spectral density of the observable variables implied by the DSGE model evaluated at each 5000th posterior draw and use an inverse difference filter to obtain the spectrum for the level of output, investment, consumption, wages, and net worth. We define business cycle fluctuations as those corresponding to cycles between 6 and 
32 quarters and consider 500 bins for frequencies covering these periodicities. We report the median variance decomposition.

First of all, we conclude that financial shocks are the main source of the variance of investment, nominal interest rate, credit spread, and business wealth. In particular, financial shocks explain up to $68 \%$ of investment variance in the 1970s. During the Great Moderation, the improvement of financial institutions translates into a reduction in the relative role of financial shocks accounting for $40 \%$ of investment variance. Financial shocks account, on average, for $50 \%$ of the fluctuations in the nominal interest rate. These shocks are the soloists orchestrating the variance of financial variables. While the wealth shock is the main driver of business cycle fluctuations of business wealth, the shock to the marginal bankruptcy cost accounts for most of the variation in credit spreads. On their estimation of a partial equilibrium version of the BGG model using micro data, Levin, Natalucci, and Zakrajšsek (2004) also obtained that exogenous disturbances in the marginal bankruptcy cost are the main driver of the external finance premium. Therefore, we conclude that models with the financial accelerator aiming at providing empirically plausible swings in the cost of external financing should explore time variation in the level of financial rigidity.

Financial shocks also play a remarkable secondary role as drivers of inflation, hours, and consumption. Their relative importance importance, however, has declined significantly during the Great Moderation. Financial shocks account for almost $20 \%$ of inflation variance pre-1984 and only 10\% afterward. During the Great Inflation, $27 \%$ of the variance in hours is explained by financial shocks. Such a percentage declines to $10 \%$ in the mid-1980s. The relative contribution of financial shocks to the variance of consumption is in the 10-18\% range. These shocks also play a non-negligible role as drivers of business cycle fluctuations of output accounting for up to $19 \%$ of output variance during the Great Inflation.

Second, conversely to the standard results in the literature, our estimates deliver a negligible role for the investment specific technology shock as driver of the business cycle. Once financial frictions and financial shocks are at play, the I-shock is just a shifter of the relative price of capital goods. Therefore, it is relegated to account for a small fraction of the variance of nominal variables and business wealth. Justiniano, Primiceri, and Tambalotti (2011) consider two types of investment shocks: investment-specific technology shocks affecting the transformation of consumption into investment goods and shocks to the marginal efficiency of investment which ultimately affect the transformation of investment goods into productive capital. They conclude that the relative importance of the former is negligible, but the latter is the main driver of the real business cycle. They state that shocks to the 
marginal efficiency of investment are a proxy for disturbances to the intermediation ability of the financial system. Our results confirm their conclusions since (i) financial shocks play a significant role as drivers of real and nominal cycles and (ii) the price shifter is not relevant. Conversely to Justiniano, Primiceri, and Tambalotti (2011), we do not use a one-to-one identification of the investment technology shock with the observed relative price of investment. This difference can account for the discrepancy on the relative role played by such shock as driver of nominal variables.

Third, business cycle fluctuations of output and consumption are mostly driven by the neutral technology shock and the wage markup shock. The relative importance of the former is along the lines of the literature. The large role played by wage markup shocks is due to the fact that they are the main driver of the variance in hours. On the one hand, as stated before in the text, wage markup shocks are observationally equivalent to labor supply shocks. Thus, they are expected to play a main role in the variance of hours. On the other hand, the estimated labor share of output is very large which implies that the drivers of fluctuations at business cycle frequencies in hours play a significant role in output variance. We should highlight that the percentage of the total variance of output, consumption, and wages explained by the neutral technology shock is smaller during the Great Moderation.

6.2 Impulse response functions: The propagation of real and nominal shocks in the context of a model of the financial accelerator has already been studied in the literature. Therefore, in this section, we focus only on the study of the propagation dynamics of financial shocks. For both the wealth shock and the innovation to the marginal bankruptcy cost, we plot the responses in the first 50 quarters in terms of percentage deviations with respect to the steady state. Each plot contains three impulse response functions (IRFs). The dotted line is the IRF computed using the parameter vector characterizing the 1954:Q4-1970:Q1 sample period. The dashed line is the IRF for the 1970s and early 1980s. The solid line is the IRF of the post-1984 period.

\section{Wealth shock}

Figure 1 reports the impulse response functions following a wealth shock that, upon impact, induces an increase in entrepreneurial net worth equal to a $1 \%$ deviation from its steady-state value in the pre-Great Inflation era. The size of the shock generating such a response upon impact is 0.46 . We use the same shock across sub-samples to facilitate the comparison. The main messages from the figure are: (i) the impulse response functions in the 1954-1970 and 1970-1984 are very similar for all variables with only remarkable differences for investment, interest rates, and the finance premium; (ii) responses upon impact are a 
positive function of the size of the financial rigidity; and (iii) the responses become more persistent post-1984.

Let us first analyze the impulse response functions for the pre-1984 sample periods. The response upon impact of net worth is an $8 \%$ larger during the Great Inflation but after 8 quarters the IRF associated with the 1950s-1960s lays above the one for the Great Inflation. They peak at adjacent quarters, 12 and 11 respectively, and the value at the peak during the Great Inflation is $1 \%$ lower than in the previous period. Given the similarities, we proceed by discussing the IRFs of the pre-1984 subsamples together. The response of net worth is very persistent, which is the source of the large contribution of the wealth shock to the low frequency fluctuations of entrepreneurial wealth. A positive wealth shock that increases the value of collateral reduces the probability of default so that financial intermediaries are willing to lend at a lower premium. Therefore, the response of the external finance premium upon impact is negative. This immediate improvement in credit markets has a significant amplification effect on investment so that the response of investment upon impact is 5-6\% above its steady state value. The initial response of output is positive but smaller than the boost in investment because consumption decreases upon impact and the total resources constraint needs to be satisfied. The negative response of consumption upon impact is linked to the general equilibrium effects of our model. A nonfundamental increase in entrepreneurial wealth is financed through a reduction in household wealth. The reduction in total disposable income is not large enough to generate a decrease in consumption of the same magnitude as the increase in entrepreneurial wealth. This is due to the fact that other sources of household wealth, such as labor income, react positively to the wealth shock. The positive response of inflation and the nominal interest rate suggests that the wealth shock displays the features of a standard demand shock: quantities and prices move in the same direction, leading to a tightening of monetary policy.

In the Great Moderation era, the response of net worth to the same wealth shock is about $40 \%$ lower at impact but peaks at a value $12 \%$ higher and with a lag of five quarters. From the ninth quarter onward, the response function post-1984 always lies above those for the pre-1984 sample periods. All of this can be easily reconciled from the definition of aggregate net worth. Lower average agency costs alleviate the deadweight loss associated with bankruptcy, $\mu_{t} G\left(\bar{\omega}_{t}\right) P_{t-1} R_{t}^{k} Q_{t-1} K_{t}$, which implies that for the same initial increase in wealth, the effects are more long-lasting, since more resources are accumulated from period to period. Higher persistence induced by the lower dependence on the financial accelerator mechanism translates into more persistent responses for all variables. For example, it takes to 
net worth more than 200 periods to return to its steady state value. Therefore, the persistence implied by the financial accelerator is a negative function of the size of financial rigidity. The responses for all variables are also characterized by a significantly smaller response upon impact. This is driven by the smaller size of the financial accelerator mechanism. Lower levels of credit market imperfections reduce the elasticity of the external finance premium with respect to the leverage ratio. Therefore, the amplification effect linked to the improvement in credit market conditions is more muted.

\section{Shock to the marginal bankruptcy cost}

Figure 2 reports the impulse response functions to shocks to the marginal bankruptcy cost. A negative shock to agency costs reduces the deadweight loss associated with bankruptcy. Thus, as all other defining components of net worth are predetermined, we can conclude that the response upon impact to a shock reducing the agency problem must be positive for business wealth. We focus on a negative shock that generates an increase upon impact in net worth of $1 \%$ in the pre-Great Inflation period. The size of such a shock is 85 which is 173 times larger than the wealth shock necessary to generate such a response in net worth. This shows the smaller effect in the economy of shocks to the marginal bankruptcy cost. The persistence of the propagation dynamics of a shock to the marginal bankruptcy cost is also significantly smaller than the persistence of the responses to a wealth shock.

A negative shock to agency costs creates an incentive for entrepreneurs to select contractual terms with a larger debt-to-net worth ratio, since the deadweight loss linked to bankruptcy is smaller. There are two opposing effects operating as a result of higher debtto-net worth ratios. On the one hand, both the default probability and the default productivity threshold increase, offsetting the effect of lower bankruptcy costs in determining entrepreneurial net worth. We label this effect the default effect. On the other hand, there is a mass effect that stays for the increase in capital investment linked to a larger set of resources available. Larger amounts of capital holdings imply a larger equity value through an increase in total capital returns. While the mass effect dominates the default effect at first, the second becomes the driving force after 6 quarters.

The response of investment upon impact is larger than the response we obtained to a wealth shock due to the mass effect explained above. Irrespective of the relative dominance of this effect in terms of shaping the response of entrepreneurial wealth, the increase in the pool of resources available for purchasing capital enhances investment activity in the economy. Consumption responds to the expansionary shock negatively due the fact that the over-investment with respect to the additional net worth available must be financed with 
higher debt. In our model, financial debt is funded through households deposits. Therefore, the amount of resources available for household consumption decreases when there is an improvement in the conditions of access to credit for firms.

Given the significant decline in the size of the financial accelerator, the post-1984 impulse response functions are all characterized by smaller responses for all variables.

\section{Conclusions}

We have estimated a fairly large DSGE model to reexamine the sources of the observed breaks in macroeconomic fluctuations in the US economy. Our estimation indicates that while the Great Inflation was mostly due to bad luck, the Great Moderation is the result of changes in the institutional framework. Conversely to the widespread view, however, improvements in the financial system, not changes in the conduct of monetary policy, are the key for the slowdown of fluctuations at business cycle frequencies. Easier access to credit since the mid1980s has been paired up with a higher average credit spread and larger financial shocks. These latter two are the mechanisms needed by the model in order to be able to replicate the immoderation observed in financial quantity measures.

Our exploration of the drivers of the US business cycle delivers that financial shocks play a significant role. In particular, they are the main driver of the variances of financial variables, investment, and the nominal interest rate. Financial shocks play a solid secondary role as drivers of fluctuations at business cycle frequencies for output, consumption, hours, and inflation. Our results highlight the irrelevance of the investment-specific technology shock as driver of the US business cycle once financial rigidities and financial shocks are at play.

Our study reaffirms the growing convention in the literature on integrating credit market imperfections in otherwise standard macroeconomic models. We have documented the importance of including financial shocks in the analysis. Moreover, we highlight the relevance of taking into account structural breaks in the data, since our conclusions, in terms of assessing the main drivers of the cycle or characterizing the propagation dynamics of shocks, may differ significantly. 


\section{References}

Alderson, M., And B. Betker (1995): "Liquidation Costs and Capital Structure," Journal of Financial Economics, 39, 45-69.

Altman, E., And B. Pasternack (2006): "Defults and Returns in the High Yield Bond Market: The Year 2005 in Review and Market Outlook," Journal of Applied Research in Accounting and Finance, 1(1), 3-30.

Altman, E. I. (1984): "A Further Investigation of the Bankruptcy Cost Question," Journal of Finance, 39(4), 1067-89.

BAi, J., And P. Perron (1998): "Estimating and Testing Linear Models With Multiple Structural Changes," Econometrica, 66(1), 47.

Carlstrom, C., and T. Fuerst (1997): "Agency Costs, Net Worth, and Business Fluctuations: A Computable General Equilibrium Analysis," American Economic Review, 87(5), 893-910.

Champagne, J., and A. Kurmann (2011): "The Great Increase in Relative Volatility of Real Wages in the United States," Mimeo.

Chow, G. C. (1960): "Tests of Equality Between Sets of Coefficients in Two Linear Regressions," Econometrica, 28(3), 591.

Christensen, I., And A. DiB (2008): "The Financial Accelerator in an Estimated New Keynesian Model," Review of Economic Dynamics, 11, 155-178.

Christiano, L., R. Motto, and M. Rostagno (2003): "The Great Depression and the Friedman-Schwartz Hypothesis," Journal of Money, Credit, and Banking, 35(6 (Part 2)), 1119-1197.

(2010): "Financial Factors in Economic Fluctuations," European Central Bank WP 1192.

DiB, A. (2009): "Banks, Credit Market Frictions, and Business Cycles," mimeo.

Erceg, C. J., D. W. Henderson, And A. T. Levin (2000): "Optimal Monetary Policy with Staggered Wage and Price Contracts," Journal of Monetary Economics, 46(2), 281313. 
Gali, J., And T. V. Rens (2010): "The Vanishing Procyclicality of Labor Productivity," Mimeo.

Gilchrist, S., And J. Leahy (2002): "Monetary Policy and Asset Prices," Journal of Monetary Economics, 49, 75-97.

Gilchrist, S., A. Ortiz, and E. ZakrajS̆EK (2009): "Credit Risk and the Macroeconomy: Evidence from an Estimated DSGE Model," mimeo.

Greenwood, J., Z. Hercowitz, and P. Krusell (2000): "The Role of InvestmentSpecific Technological Change in the Business Cycle," European Economic Review, 44, $91-115$.

Justiniano, A., G. Primiceri, and A. Tambalotti (2011): "Investment Shocks and the Relative Price of Investment," Review of Economic Dynamics, 14(1), 101-121.

Levin, A., F. NAtalucci, And E. ZakrajS̆EK (2004): "The Magnitude and Cyclical Behvior of Financial Market Frictions," Finance and Economics Discussion Series. Division of Research \& Statistics and Monetary Affairs, Federal Reserve System, Board of Governors, 2004-70.

McConnell, M. M., And G. PÉrez-Quirós (2000): "Output Fluctuations in the United States: What Has Changed Since the Early 1980's?," American Economic Review, 90(5), $1464-1476$.

Nolan, C., And C. Thoenissen (2009): "Financial shocks and the US business cycle," Journal of Monetary Economics, 56(4), 596-604.

Smets, F., And R. Wouters (2007): "Shocks and Frictions in US Business Cycles: A Bayesian DSGE Approach," American Economic Review, 97, 586-606.

Townsend, R. (1979): "Optimal Contracts and Competitive Markets with Costly State Verification," Journal of Economic Theory, 21, 265-293.

White, M. J. (1983): "Bankruptcy Costs and the New Bankruptcy Code," Journal of Finance, XXXVIII(2), 477-488. 


\section{A Tables and Figures}

Table A-1: Econometric tests

\begin{tabular}{|c|c|c|c|c|c|c|}
\hline & \multicolumn{4}{|c|}{ BAI-PERRON } & \multicolumn{2}{|c|}{ CHOW } \\
\hline & Raw & data & Cyclic & l data & Raw data & Cyclical data \\
\hline Output & 1983:Q4 & & 1984:Q2 & & $33.45^{* * *}$ & $34.60^{* * *}$ \\
\hline Investment & 1984:Q2 & & 1984:Q2 & & $18.25^{* * *}$ & $21.83^{* *}$ \\
\hline Consumption & 1984:Q2 & & 1984:Q2 & & $11.98 * * *$ & $19.54^{* * *}$ \\
\hline Wage & 1997:Q3 & & 1996:Q3 & & $5.71^{*}$ & $11.38 * * *$ \\
\hline Hours & - & & - & & $9.80^{* * *}$ & $19.01^{* * *}$ \\
\hline Inflation & 1970:Q1 & 1981:Q2 & 1970:Q1 & 1981:Q2 & $32.06^{* * *}$ & $42.95^{* *}$ \\
\hline Federal Funds Rate & 1970:Q2 & 1982:Q4 & 1972:Q4 & 1983:Q1 & $54.45^{* *}$ & $44.66^{* * *}$ \\
\hline Net worth (firms) & 1988:Q4 & & 1988:Q4 & & $17.26^{* * *}$ & $13.82^{* * *}$ \\
\hline Net worth (households) & 1997:Q1 & & 1997:Q4 & & 3.05 & 3.59 \\
\hline Net private savings & 1998:Q3 & & 1998:Q4 & & $6.33^{* *}$ & $10.41^{* * *}$ \\
\hline Demand deposits & 1980:Q1 & & 1980:Q1 & & $14.44^{* * *}$ & $16.13^{* * *}$ \\
\hline Checkable deposits & 1997:Q2 & & 1997:Q2 & & $22.27 * * *$ & $15.46^{* * *}$ \\
\hline Spread: Baa-Aaa & 1974:Q3 & 1985:Q2 & 1974:Q3 & 1985:Q2 & $42.52^{* * *}$ & $31.98 * * *$ \\
\hline Spread: Baa-ffr & 1972:Q4 & 1982:Q3 & 1969:Q1 & 1982:Q3 & $37.87^{* * *}$ & $39.69 * * *$ \\
\hline Spread: Baa-10y & 1970:Q1 & 1984:Q2 & 1970:Q1 & 1983:Q4 & $29.36^{* * *}$ & $35.22^{* * *}$ \\
\hline Wilshire 5000 index & 1997:Q2 & & 1997:Q2 & & & \\
\hline
\end{tabular}

Notes: Data on output, consumption, investment, net worth, debt, deposits, and savings is in real per capita terms. Raw data for output, consumption, investment, wages, net worth, debt, demand deposits, net private savings, and Wilshire 5000 Index stands for growth rates. The data ranges from 1954:Q4 to 2006:Q4 for all variables but demand deposits which is available since 1959 and the Wilshire 5000 index which is available since 1971:Q1. The cyclical component is extracted using the Hodrick-Prescott filter for the quarterly frequency $(\lambda=1600)$. The log-likelihood ratio statistic is distributed as $\chi^{2}$ with $(m-1) k$ degrees of freedom, where $m$ is the number of subsamples. The critical values when there are two breaks are 4.61 at $10 \%, 5.99$ at $5 \%$, and 9.21 at $1 \%$. If the statistic is above the critical value, the null hypothesis of no structural change can be rejected. The symbol * indicates we can reject the null of parameter constancy at $10 \%,{ }^{* *}$, at $5 \%$, and ${ }^{* * *}$, at $1 \%$. 
Table A-2: Ratio of Standard deviations

\begin{tabular}{|ccc|cc|}
\hline & \multicolumn{2}{c|}{ Raw data } & \multicolumn{2}{c|}{ Cyclical component } \\
\hline & $\frac{1970-1984}{1954-1970}$ & $\frac{1984-2006}{1970-1984}$ & $\frac{1970-1984}{1954-1970}$ & $\frac{1984-2006}{1970-1984}$ \\
\hline Output & 1.10 & 0.42 & 1.58 & 0.42 \\
Investment & 1.09 & 0.49 & 1.46 & 0.51 \\
Consumption & 1.20 & 0.53 & 1.74 & 0.44 \\
Wage & 1.15 & 1.27 & 1.39 & 1.21 \\
Hours & 1.05 & 1.26 & 1.47 & 0.64 \\
Inflation & 2.05 & 0.37 & 2.56 & 0.36 \\
Federal Funds Rate & 2.02 & 0.64 & 2.64 & 0.50 \\
Net worth (firms) & 1.31 & 1.48 & 1.30 & 1.47 \\
Net worth (households) & 1.19 & 1.19 & 1.92 & 1.07 \\
Net private savings & 1.35 & 1.40 & 1.10 & 1.44 \\
Demand deposits & 2.77 & 1.10 & 4.44 & 1.05 \\
Checkable deposits & 1.05 & 1.97 & 1.39 & 2.41 \\
Spread: Baa-Aaa & 3 & 0.58 & 3 & 0.33 \\
Spread: Baa-ffr & 2.50 & 0.60 & 2.65 & 0.47 \\
Spread: Baa-10y & 2.29 & 0.75 & 2.33 & 0.50 \\
Wilshire 5000 index & & 5.68 & & 7.51 \\
\hline
\end{tabular}

Notes: Data on output, consumption, investment, net worth, debt, deposits, and savings is in real per capita terms. Raw data for output, consumption, investment, wages, net worth, debt, demand deposits, net private savings, and Wilshire 5000 Index stands for growth rates. The Wilshire 5000 index which is available since 1971:Q1. The cyclical component is extracted using the Hodrick-Prescott filter for the quarterly frequency $(\lambda=1600)$. The standard deviations have been multiplied by 100

Table A-3: Model Fit: Ratio of standard deviations. Cyclical component.

\begin{tabular}{|c|ccc|ccc|}
\hline Series & \multicolumn{3}{|c|}{$\frac{1970-1984}{1954-1970}$} & \multicolumn{3}{c|}{$\frac{1984-2006}{1970-1984}$} \\
\hline & Data & \multicolumn{2}{|c|}{ Model } & \multicolumn{3}{c|}{ Model } \\
& \multicolumn{3}{|c|}{ Median } & $90 \%$ & & \multicolumn{3}{c|}{ Median } & $90 \%$ \\
\hline Output & 1.58 & 1.50 & {$[1.34,1.67]$} & 0.42 & 0.60 & {$[0.55,0.66]$} \\
Investment & 1.46 & 1.89 & {$[1.62,2.12]$} & 0.51 & 0.58 & {$[0.51,0.63]$} \\
Consumption & 1.74 & 1.24 & {$[1.10,1.37]$} & 0.44 & 0.66 & {$[0.59,0.73]$} \\
Wage & 1.39 & 1.47 & {$[1.26,1.73]$} & 1.21 & 0.65 & {$[0.56,0.78]$} \\
Hours & 1.47 & 1.51 & {$[1.34,1.68]$} & 0.64 & 0.59 & {$[0.54,0.66]$} \\
Inflation & 2.56 & 2.38 & {$[2.00,2.82]$} & 0.36 & 0.37 & {$[0.30,0.44]$} \\
Nominal interest rate & 2.64 & 2.12 & {$[1.78,2.36]$} & 0.50 & 0.41 & {$[0.36,0.47]$} \\
Net worth & 1.30 & 1.39 & {$[1.17,1.69]$} & 1.47 & 1.28 & {$[1.04,1.52]$} \\
Spread & 2.65 & 3.05 & {$[2.52,3.65]$} & 0.47 & 0.34 & {$[0.28,0.40]$} \\
\hline
\end{tabular}

Notes: For each 1000th parameter draw, we generate 100 samples with the same length as the data after discarding 1000 initial observations. We HP filter the non-stationary data generated by the model. 
Table A-4: Parameters estimated using the full sample

\begin{tabular}{|c|ccc|cc|}
\hline & \multicolumn{3}{|c|}{ Prior } & \multicolumn{2}{c|}{ Posterior } \\
\hline & Density & Para 1 & Para 2 & Median & $\mathbf{9 5 \%}$ CI \\
\hline$\delta$ & Fixed & 0.025 & & & \\
$\left(\frac{G}{Y}\right)^{\star}$ & Fixed & 0.22 & & & \\
{$[F(\bar{\omega})]^{\star}$} & Fixed & 0.0075 & & & \\
$\sigma_{\omega}^{2}$ & Fixed & 0.24 & & & \\
$100[1 / \beta-1]$ & $\mathcal{G}$ & 0.25 & 0.10 & 0.16 & {$[0.06,0.27]$} \\
$100[1 / \gamma-1]$ & $\mathcal{G}$ & 1.48 & 0.50 & 2.18 & {$[0.96,3.57]$} \\
$\pi_{n}^{\star}$ & $\mathcal{N}$ & 3.00 & 1.00 & 2.62 & {$[2.19,3.07]$} \\
$100 \ln \left(H^{\star}\right)$ & $\mathcal{N}$ & 0.50 & 0.40 & 0.45 & {$[-0.33,1.25]$} \\
$100 \Upsilon_{z}$ & $\mathcal{N}$ & 0.50 & 1.00 & 0.44 & {$[0.29,0.58]$} \\
$\phi=\Phi / y_{\star}$ & Beta & 0.15 & 0.05 & 0.26 & {$[0.16,0.36]$} \\
$\lambda_{p}$ & Beta & 0.15 & 0.05 & 0.40 & {$[0.28,0.51]$} \\
$\lambda_{w}$ & Beta & 0.15 & 0.05 & 0.18 & {$[0.08,0.29]$} \\
$\iota_{p}$ & Beta & 0.50 & 0.15 & 0.10 & {$[0.02,0.22]$} \\
$\iota_{w}$ & Beta & 0.50 & 0.15 & 0.36 & {$[0.19,0.56]$} \\
$\xi_{p}$ & Beta & 0.75 & 0.2 & 0.51 & {$[0.41,0.59]$} \\
$\xi_{w}$ & Beta & 0.70 & 0.2 & 0.08 & {$[0.04,0.13]$} \\
$\alpha$ & Beta & 0.30 & 0.025 & 0.15 & {$[0.13,0.17]$} \\
$\xi$ & $\mathcal{N}$ & 1.50 & 0.25 & 2.46 & {$[2.07,2.85]$} \\
$\mathrm{a}^{\prime}$ & $\mathcal{G}$ & 0.50 & 0.25 & 0.49 & {$[0.13,1.02]$} \\
$\nu$ & $\mathcal{G}$ & 2 & 1 & 1.40 & {$[0.77,2.52]$} \\
$h$ & Beta & 0.50 & 0.10 & 0.52 & {$[0.46,0.58]$} \\
$\rho_{r}$ & Beta & 0.50 & 0.10 & 0.80 & {$[0.77,0.84]$} \\
$\rho_{z}$ & Beta & 0.40 & 0.10 & 0.16 & {$[0.09,0.24]$} \\
$\rho_{\zeta}$ & Beta & 0.60 & 0.20 & 0.93 & {$[0.89,0.96]$} \\
$\rho_{\mu}$ & Beta & 0.60 & 0.20 & 0.84 & {$[0.79,0.88]$} \\
$\rho_{x}$ & Beta & 0.60 & 0.20 & 0.90 & {$[0.84,0.95]$} \\
$\rho_{\lambda_{p}}$ & Beta & 0.60 & 0.20 & 0.9912 & {$[0.9806,0.9995]$} \\
$\rho_{\lambda_{w}}$ & Beta & 0.60 & 0.20 & 0.9911 & {$[0.9814,0.9988]$} \\
$\rho_{b}$ & Beta & 0.60 & 0.20 & 0.92 & {$[0.88,0.95]$} \\
$\rho_{g}$ & Beta & 0.60 & 0.20 & 0.98 & {$[0.97,0.99]$} \\
\hline & & & & & \\
\hline
\end{tabular}

Notes: Para 1 and Para 2 list the means and the standard deviations for Beta, Gamma, and Normal distributions; the upper and lower bound of the support for the Uniform distribution; s and $\nu$ for the Inverse Gamma distribution, where $p_{I G}(\sigma \mid \nu, s) \propto \sigma^{-\nu-1} e^{-n u s^{2} / 2 \sigma^{2}}$. The effective prior is truncated at the boundary of the determinacy region. 
Table A-5: Parameters subject to structural breaks

\begin{tabular}{|c|c|c|c|c|c|}
\hline & \multicolumn{3}{|c|}{ Prior } & \multicolumn{2}{|c|}{ Posterior } \\
\hline & Density & Para 1 & Para 2 & Median & $95 \% \mathrm{CI}$ \\
\hline$\psi_{\pi_{1}}$ & $\mathcal{N}$ & 1.50 & 0.50 & 2.00 & {$[1.69,2.36]$} \\
\hline$\psi_{\pi_{2}}$ & $\mathcal{N}$ & 1.50 & 0.50 & 1.94 & {$[1.63,2.29]$} \\
\hline$\psi_{\pi_{3}}$ & $\mathcal{N}$ & 1.50 & 0.50 & 2.32 & {$[1.94,2.78]$} \\
\hline$\psi_{y_{1}}$ & $\mathcal{N}$ & 0.50 & 0.30 & 0.29 & {$[0.18,0.41]$} \\
\hline$\psi_{y_{2}}$ & $\mathcal{N}$ & 0.50 & 0.30 & 0.51 & {$[0.31,0.72]$} \\
\hline$\psi_{y_{3}}$ & $\mathcal{N}$ & 0.50 & 0.30 & 0.51 & {$[0.32,0.70]$} \\
\hline$\mu_{1}^{\star}$ & Beta & 0.28 & 0.05 & 0.17 & {$[0.11,0.24]$} \\
\hline$\mu_{2}^{\star}$ & Beta & 0.28 & 0.05 & 0.24 & {$[0.18,0.32]$} \\
\hline$\mu_{3}^{\star}$ & Beta & 0.28 & 0.05 & 0.05 & {$[0.03,0.06]$} \\
\hline $400\left[\left(R_{\star}^{k} / R_{\star}\right)_{1}-1\right]$ & $\mathcal{N}$ & 2.40 & 1.00 & -1.21 & {$[-1.88,-0.52]$} \\
\hline $400\left[\left(R_{\star}^{k} / R_{\star}\right),-1\right]$ & $\mathcal{N}$ & 2.40 & 1.00 & 0.73 & {$[-0.08,1.54]$} \\
\hline $400\left[\left(R_{\star}^{k} / R_{\star}\right)_{3}-1\right]$ & $\mathcal{N}$ & 2.40 & 1.00 & 2.34 & {$[1.71,3.05]$} \\
\hline$\sigma_{\mu_{1}}$ & $\mathcal{I G}$ & 1 & 4 & 0.27 & {$[0.16,0.39]$} \\
\hline$\sigma_{\mu_{2}}$ & $\mathcal{I G}$ & 1 & 4 & 0.63 & {$[0.45,0.86]$} \\
\hline$\sigma_{\mu_{3}}$ & $\mathcal{I G}$ & 1 & 5 & 1.11 & {$[0.72,1.48]$} \\
\hline $100\left(\sigma_{x_{1}}\right)$ & $\mathcal{I G}$ & 1 & 4 & 0.43 & {$[0.34,0.53]$} \\
\hline $100\left(\sigma_{x_{2}}\right)$ & $\mathcal{I G}$ & 1 & 4 & 0.54 & {$[0.42,0.69]$} \\
\hline $100\left(\sigma_{x_{3}}\right)$ & $\mathcal{I G}$ & 1 & 4 & 1.03 & {$[0.79,1.28]$} \\
\hline $100\left(\sigma_{z_{1}}\right)$ & $\mathcal{I G}$ & 1 & 4 & 1.24 & {$[1.04,1.47]$} \\
\hline $100\left(\sigma_{z_{2}}\right)$ & $\mathcal{I G}$ & 1 & 4 & 1.23 & {$[1.02,1.47]$} \\
\hline $100\left(\sigma_{z_{3}}\right)$ & $\mathcal{I G}$ & 1 & 4 & 0.85 & {$[0.73,0.98]$} \\
\hline $100\left(\sigma_{\zeta_{1}}\right)$ & $\mathcal{I G}$ & 1 & 4 & 0.71 & {$[0.57,0.87]$} \\
\hline $100\left(\sigma_{\zeta_{2}}\right)$ & $\mathcal{I G}$ & 1 & 4 & 0.90 & {$[0.74,1.09]$} \\
\hline $100\left(\sigma_{\zeta_{3}}\right)$ & $\mathcal{I} \mathcal{G}$ & 1 & 4 & 0.74 & {$[0.60,0.90]$} \\
\hline $100\left(\sigma_{\lambda_{1}^{p}}\right)$ & $\mathcal{I G}$ & 1 & 4 & 3.37 & {$[2.53,4.42]$} \\
\hline $100\left(\sigma_{\lambda_{p}^{p}}\right)$ & $\mathcal{I G}$ & 1 & 4 & 4.68 & {$[3.37,6.31]$} \\
\hline $100\left(\sigma_{\lambda_{3}^{p}}\right)$ & $\mathcal{I} \mathcal{G}$ & 1 & 4 & 3.34 & {$[2.48,4.37]$} \\
\hline $100\left(\sigma_{\lambda_{1}^{w}}\right)$ & $\mathcal{I G}$ & 1 & 4 & 2.57 & {$[1.90,3.61]$} \\
\hline $100\left(\sigma_{\lambda_{2}^{w}}\right)$ & $\mathcal{I G}$ & 1 & 4 & 3.16 & {$[2.28,4.57]$} \\
\hline $100\left(\sigma_{\lambda_{3}^{w}}\right)$ & $\mathcal{I G}$ & 1 & 4 & 2.31 & {$[1.74,3.18]$} \\
\hline $100\left(\sigma_{b_{1}}\right)$ & $\mathcal{I G}$ & 1 & 4 & 1.61 & {$[1.18,2.18]$} \\
\hline $100\left(\sigma_{b_{2}}\right)$ & $\mathcal{I G}$ & 1 & 4 & 2.85 & {$[2.10,3.79]$} \\
\hline $100\left(\sigma_{b_{3}}\right)$ & $\mathcal{I} \mathcal{G}$ & 1 & 4 & 1.45 & {$[1.09,1.94]$} \\
\hline $100\left(\sigma_{r_{1}}\right)$ & $\mathcal{I G}$ & 0.1 & 4 & 0.12 & {$[0.10,0.15]$} \\
\hline $100\left(\sigma_{r_{2}}\right)$ & $\mathcal{I G}$ & 0.1 & 4 & 0.39 & {$[0.31,0.48]$} \\
\hline $100\left(\sigma_{r_{3}}\right)$ & $\mathcal{I} \mathcal{G}$ & 0.1 & 4 & 0.13 & {$[0.11,0.16]$} \\
\hline $100\left(\sigma_{g_{1}}\right)$ & $\mathcal{I G}$ & 0.1 & 4 & 0.47 & {$[0.38,0.56]$} \\
\hline $100\left(\sigma_{g_{2}}\right)$ & $\mathcal{I} \mathcal{G}$ & 0.1 & 4 & 0.49 & {$[0.41,0.58]$} \\
\hline $100\left(\sigma_{g_{3}}\right)$ & $\mathcal{I G}$ & 0.1 & 4 & 0.37 & {$[0.32,0.43]$} \\
\hline
\end{tabular}

Notes: Para 1 and Para 1 list $\mathrm{s}$ and $\nu$ for the Inverse Gamma distribution, where $p_{I G}(\sigma \mid \nu, s) \propto$ $\sigma^{-\nu-1} e^{-n u s^{2} / 2 \sigma^{2}}$. The effective prior is truncated at the boundary of the determinacy region. 


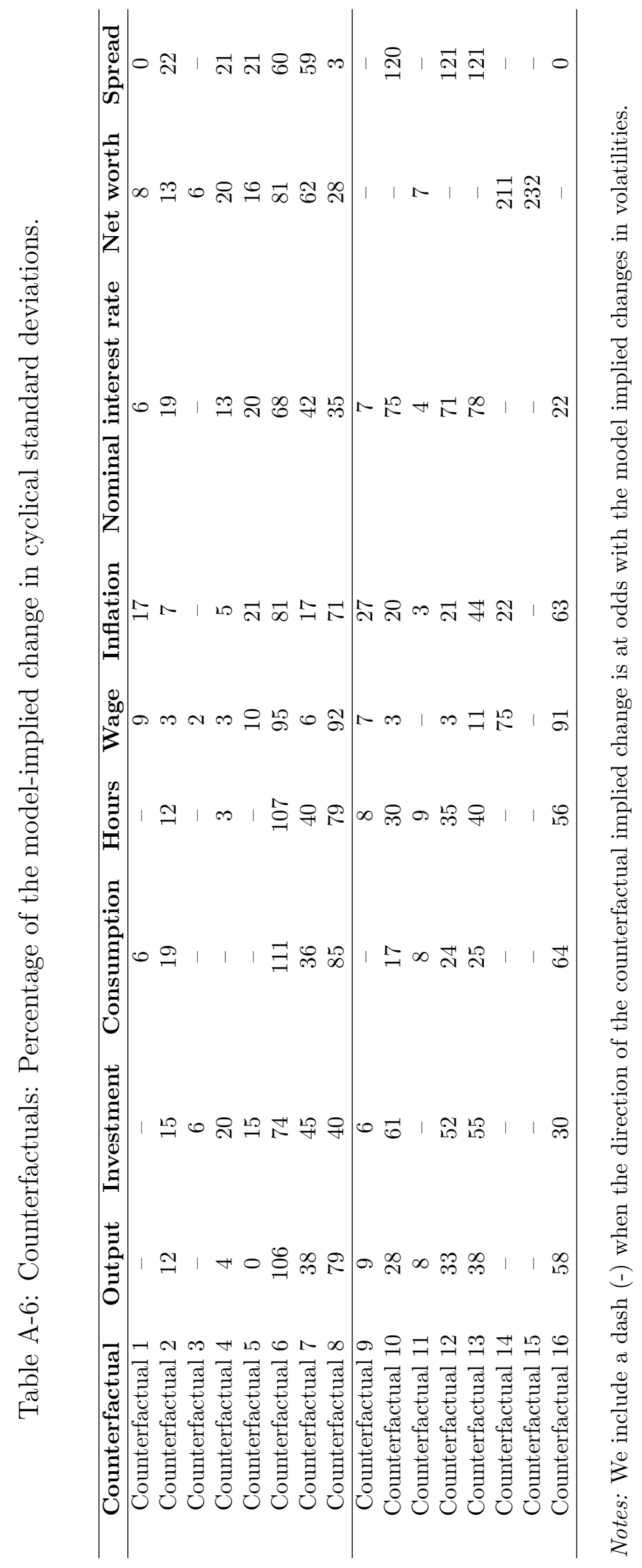

A- 5 
Table A-7: Variance decomposition at business cycle frequencies: Medians

\begin{tabular}{|c|c|c|c|c|c|c|c|c|c|}
\hline \multicolumn{10}{|c|}{ Output } \\
\hline & Bank. cost & Wealth & Neutral & I-shock & P-Markup & W-markup & Inter & MP & Gov \\
\hline Pre-1970 & 2 & 7 & 46 & 1 & 10 & 30 & 1 & 1 & 2 \\
\hline 1970-1984 & 11 & 8 & 29 & 0 & 12 & 29 & 1 & 8 & 1 \\
\hline Post-1984 & 3 & 3 & 33 & 2 & 16 & 39 & 1 & 1 & 1 \\
\hline \multicolumn{10}{|c|}{ Investment } \\
\hline & Bank. cost & Wealth & Neutral & I-shock & P-Markup & W-markup & Inter & MP & Gov \\
\hline Pre-1970 & 8 & 47 & 14 & 3 & 10 & 5 & 12 & 2 & 0 \\
\hline $1970-1984$ & 33 & 35 & 4 & 1 & 7 & 2 & 10 & 8 & 0 \\
\hline Post-1984 & 15 & 25 & 8 & 8 & 16 & 8 & 19 & 1 & 0 \\
\hline \multicolumn{10}{|c|}{ Consumption } \\
\hline & Bank. cost & Wealth & Neutral & I-shock & P-Markup & W-markup & Inter & MP & Gov \\
\hline Pre-1970 & 1 & 13 & 40 & 1 & 3 & 34 & 6 & 0 & 4 \\
\hline $1970-1984$ & 4 & 14 & 29 & 0 & 4 & 36 & 9 & 0 & 3 \\
\hline Post-1984 & 2 & 8 & 32 & 2 & 3 & 41 & 9 & 0 & 3 \\
\hline \multicolumn{10}{|c|}{ Hours } \\
\hline & Bank. cost & Wealth & Neutral & I-shock & P-Markup & W-markup & Inter & $\mathrm{MP}$ & Gov \\
\hline Pre-1970 & 4 & 14 & 1 & 1 & 18 & 55 & 2 & 3 & 3 \\
\hline 1970-1984 & 16 & 11 & 1 & 1 & 16 & 41 & 1 & 11 & 2 \\
\hline Post-1984 & 5 & 5 & 1 & 3 & 22 & 58 & 2 & 2 & 2 \\
\hline \multicolumn{10}{|c|}{ Wage } \\
\hline & Bank. cost & Wealth & Neutral & I-shock & P-Markup & W-markup & Inter & MP & Gov \\
\hline Pre-1970 & 0 & 0 & 62 & 0 & 34 & 2 & 1 & 1 & 0 \\
\hline $1970-1984$ & 1 & 0 & 42 & 0 & 46 & 3 & 2 & 6 & 0 \\
\hline Post-1984 & 0 & 0 & 45 & 0 & 50 & 3 & 1 & 1 & 0 \\
\hline \multicolumn{10}{|c|}{ Inflation } \\
\hline & Bank. cost & Wealth & Neutral & I-shock & P-Markup & W-markup & Inter & MP & Gov \\
\hline Pre-1970 & 8 & 13 & 12 & 3 & 2 & 11 & 23 & 28 & 0 \\
\hline $1970-1984$ & 13 & 4 & 6 & 1 & 2 & 8 & 17 & 49 & 0 \\
\hline Post-1984 & 10 & 1 & 15 & 4 & 5 & 21 & 16 & 27 & 0 \\
\hline \multicolumn{10}{|c|}{ Nominal rate } \\
\hline & Bank. cost & Wealth & Neutral & I-shock & P-Markup & W-markup & Inter & $\mathrm{MP}$ & Gov \\
\hline Pre-1970 & 16 & 36 & 2 & 7 & 1 & 1 & 36 & 1 & 1 \\
\hline 1970-1984 & 42 & 19 & 0 & 2 & 1 & 1 & 34 & 1 & 1 \\
\hline Post-1984 & 35 & 11 & 1 & 17 & 3 & 1 & 30 & 1 & 1 \\
\hline \multicolumn{10}{|c|}{ Net Worth } \\
\hline & Bank. cost & Wealth & Neutral & I-shock & P-Markup & W-markup & Inter & MP & Gov \\
\hline Pre-1970 & 2 & 75 & 2 & 17 & 2 & 0 & 1 & 1 & 0 \\
\hline 1970-1984 & 14 & 64 & 1 & 14 & 2 & 0 & 1 & 5 & 0 \\
\hline Post-1984 & 1 & 92 & 0 & 4 & 1 & 0 & 1 & 0 & 0 \\
\hline \multicolumn{10}{|c|}{ Spread } \\
\hline & Bank. cost & Wealth & Neutral & I-shock & P-Markup & W-markup & Inter & MP & Gov \\
\hline Pre-1970 & 64 & 31 & 0 & 2 & 0 & 0 & 3 & 0 & 0 \\
\hline $1970-1984$ & 88 & 9 & 0 & 1 & 0 & 0 & 2 & 0 & 0 \\
\hline Post-1984 & 89 & 10 & 0 & 0 & 0 & 0 & 0 & 0 & 0 \\
\hline
\end{tabular}

Notes: It corresponds to periodic components of cycles between 6 and 32 quarters. We compute the variance decomposition for each $5000^{\text {th }}$ draw using the spectrum of the model. For output, investment, consumption, wages, and net worth, we use an inverse difference filter in order to report the decomposition for levels. We consider 500 bins for frequencies covering the periodicities of interest. 


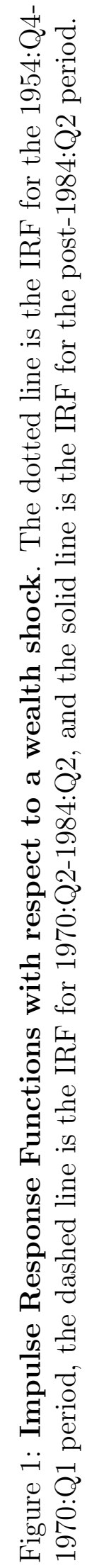
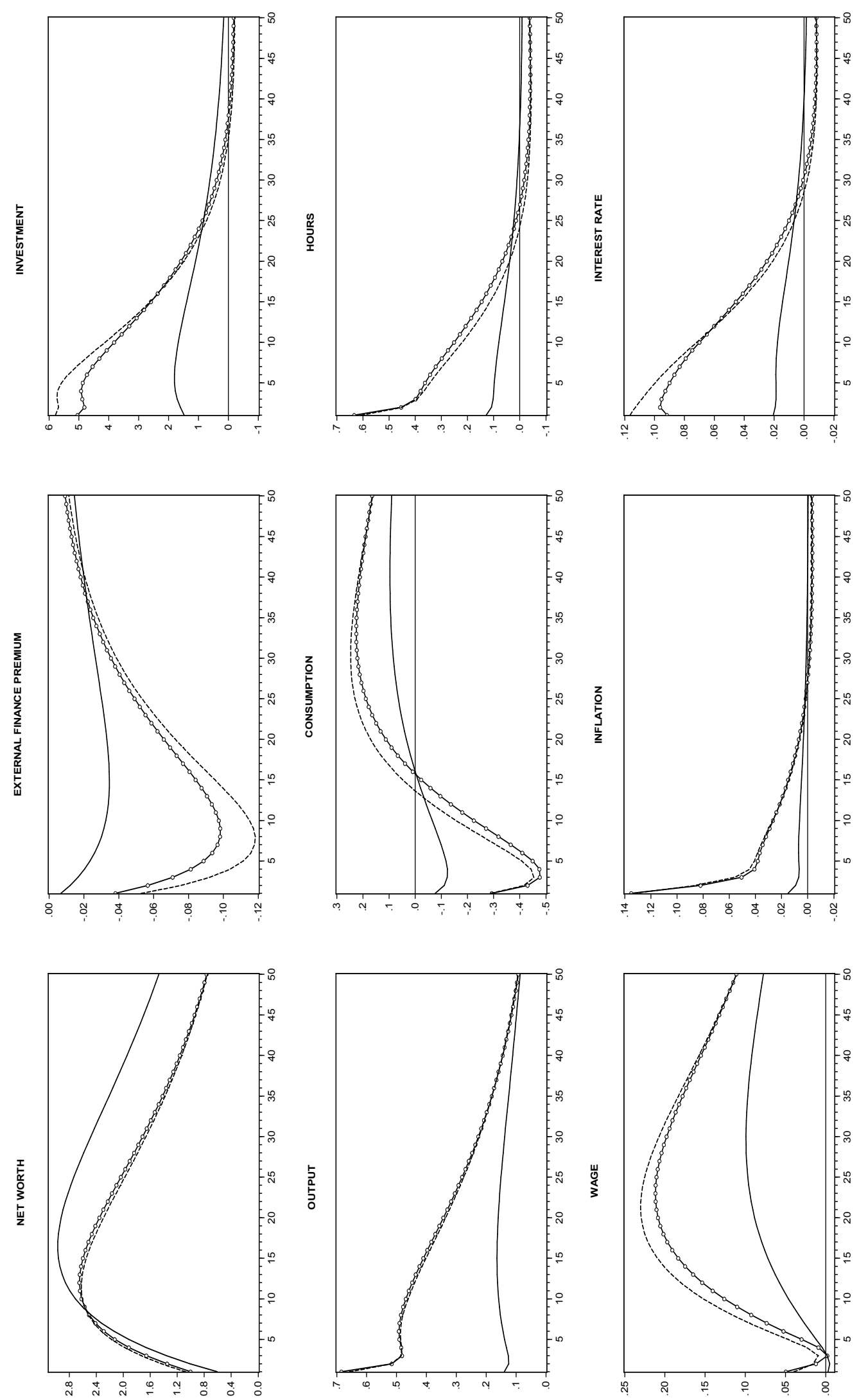

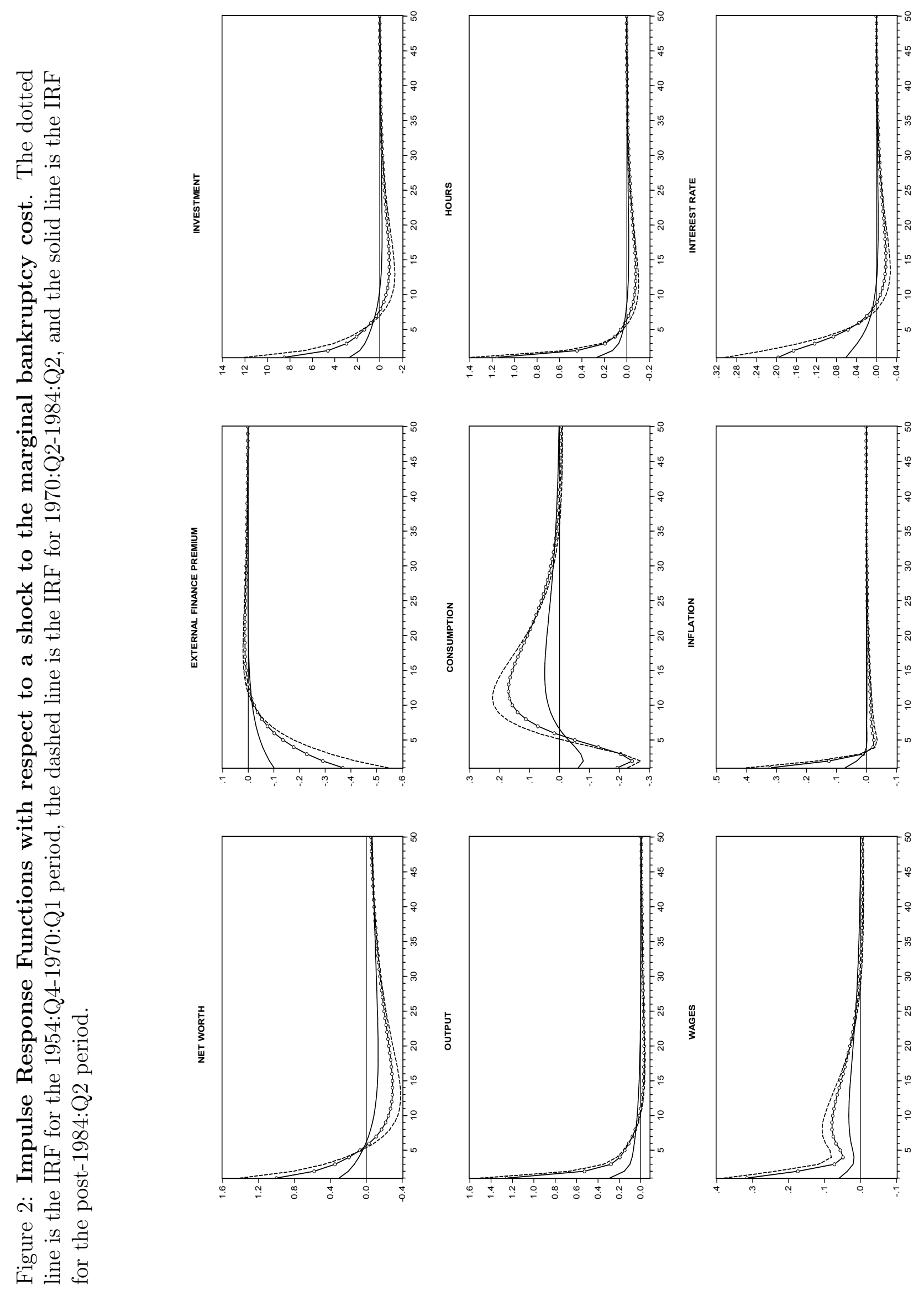